\title{
Reversible Inhibition of Voltage-dependent Outer Hair Cell Motility and Capacitance
}

\author{
J. Santos-Sacchia \\ Laboratory of Otolaryngology, UMDNJ-New Jersey Medical School, Newark, New Jersey 07103
}

Outer hair cells (OHC) from the organ of Corti are capable of fast voltage-induced length changes (Santos-Sacchi and Dilger, 1988), suggesting that an associated voltage sensor should reside in the OHC plasma membrane. Voltage-dependent mechanical responses and nonlinear charge movement of isolated OHCs from the guinea pig were analyzed using the whole-cell voltage-clamp technique. Ionic currents in the cells were blocked. Nonlinear voltage-dependent charge movement or, correspondingly, voltage-dependent capacitance was measured with step or AC analysis. OHC movements were measured either from video or using a differential photodiode technique. Maximum charge movements up to $2.5 \mathrm{pC}$ were measured in OHCs from the lowfrequency region of the cochlea. Both $A C$ and step analyses indicated a peak nontinear capacitance of 16-17 pF. The voltage dependence was fit to a Boltzmann relation with the step analysis indicating a maximum nonlinear capacitance at $-23 \mathrm{mV}$ step potential from a holding potential of about $-120 \mathrm{mV}$, and $A C$ analysis indicating a maximum at a holding potential near $-\mathbf{4 0} \mathrm{mV}$. AC analysis probably provides a more accurate evaluation of voltage dependence. Measures of OHC motility magnitude versus voltage follow the nonlinear capacitance-voltage function obtained from AC measures. Treatment of the cells with gadolinium ions (0.5$1 \mathrm{~mm}$ ) blocked $\mathrm{OHC}$ motility. This treatment also produced a shift of the nonlinear capacitance function along the voltage axis in the depolarizing direction, which can be explained by membrane surface charge screening. However, maximum capacitance was reduced as well and may correspond to the reduction or abolition of OHC motility in response to gadolinium treatment. Gadolinium effects were reversible. Nonlinear capacitance is not a function of membrane deformation due to length changes, since removal of $\mathrm{OHC}$ cytosol via the patch pipette abolished longitudinal movement but did not reduce nonlinear charge movement. It is interesting to note that the nonlinear capacitance will dynamically influence the time constant of the OHC during acoustically evoked receptor potential generation.

\footnotetext{
Received Mar. 8, 1991; revised Apr. 24, 1991; accepted May 2, 1991.

This work was supported by an NIDCD Research Career Development Award and NIH Grant DC00273. I thank Jack Callahan and Janet Santos for technical assistance, and Jont Allen, Francisco Bezanilla, and Bill Brownell for many helpful discussions. I also thank the reviewers for their constructive criticism.

Correspondence should be addressed to J. Santos-Sacchi, Ph.D., Department of Surgery, Section of Otolaryngology, Yale University School of Medicine, 333 Cedar St., New Haven, CT 06510.

a Present address: Sections of Otolaryngology and Neurobiology, Yale University School of Medicine, New Haven, CT 06510.

Copyright (c) 1991 Society for Neuroscience $0270-6474 / 91 / 113096-15 \$ 05.00 / 0$
}

Both types of hair cells within the organ of Corti, inner (IHC) and outer $(\mathrm{OHC})$, transduce mechanical movements of the basilar membrane into electrical responses. However, even though OHCs are capable of generating receptor potentials (Dallos et al., 1982) and have recently been shown to possess depolarization induced inward calcium currents (a requisite for vesicular transmitter release; Katz and Miledi, 1967; Santos-Sacchi and Dilger, 1988; Santos-Sacchi, 1989b; Lin et al., 1990), it is not certain whether OHCs participate in the direct transfer of neurally coded information to the CNS. It is certainly clear, however, that $\mathrm{OHCs}$ participate in the shaping of acoustical information that reaches the CNS. A variety of experiments have established this, including $\mathrm{OHC}$ lesion experiments (Dallos and Harris, 1978; Harrison and Evans, 1979) and crossed olivocochlear bundle (COCB) stimulation experiments (Brown and Nuttall, 1984). The participation appears to be at the level of OHC-IHC interaction. However, neither morphologic data (Iurato et al., 1976) nor indirect physiologic data (Oesterle and Dallos, 1988) indicate the existence of direct electrical interactions. The early work of Kemp (1978) on otoacoustic emissions indicated that some sort of active process occurs within the cochlea. This concept was strengthened by studies demonstrating electrically evoked acoustic emissions (Hubbard and Mountain, 1983). With the discovery of Brownell et al. (1985) that isolated $\mathrm{OHCs}$ are capable of electrically induced rapid length changes, an exciting new concept arose regarding $\mathrm{OHC}$ function-one that envisions a mechanical feedback of OHCs upon basilar membrane motion, which in turn determines the input to the inner hair cell stereocilia (Mountain et al., 1983; Patuzzi et al., 1989). Indeed, evidence suggesting a role of $\mathrm{OHCs}$ in controlling basilar membrane motion has been recently obtained (Ruggero and Rich, 1991).

Several lines of evidence indicate that the fast mechanical response of the $\mathrm{OHC}$ is voltage dependent (Santos-Sacchi and Dilger, 1988; Iwasa and Kachar, 1989). At the systems level, this voltage dependency is important for understanding the role of OHC motility in frequency selectivity and sensitivity in the mammalian inner ear, since the $\mathrm{AC}$ receptor potential generated in these cells in vivo, that is, the presumed driving force for $\mathrm{OHC}$ motility, will be attenuated above the cells' RC cutoff frequency; thus, the magnitude of mechanical response will necessarily depend upon the frequency of acoustic stimulation (see SantosSacchi, 1989c). At the cellular level, a voltage dependence of $\mathrm{OHC}$ motility suggests that a charged voltage-sensing particle should reside in the $\mathrm{OHC}$ membrane. This concept was first postulated for voltage-dependent ionic channels (Hodgkin and Huxley, 1952), and indeed, nonlinear charge movement, which implies the existence of channel-gating particle movement, is 
now known to occur during activation of a variety of ionic channels (Armstrong and Bezanilla, 1973; Bezanilla et al., 1982a; Adams et al., 1990). Recently, nonlinear charge movement (which presents itself as a voltage-dependent capacitance) has been detected in the OHC (Ashmore, 1989).

The voltage-dependent movement of the OHC cannot be blocked by a variety of treatments, including ionic channel blockcrs, mctabolic inhibitors, $\mathrm{Ca}^{2+}$-free media, and anti-cytoskeletal agents (Kachar et al., 1986; Holley and Ashmore, 1988; Santos-Sacchi and Dilger, 1988). While these data indicate that the rapid movements are not based upon a musclelike system, they have created a sense that fast voltage-dependent $\mathrm{OHC}$ movement is unstoppable, except by irreversible means. The ability to reversibly inhibit a phenomenon is an important step in understanding its underlying mechanism. I report here two methods that rapidly and reversibly diminish or abolish longitudinal $\mathrm{OHC}$ mechanical responses induced under voltage clamp. The first is treatment of OHCs with gadolinium $\left(\mathrm{Gd}^{3+}\right)$ ions, and the second is the removal of $\mathrm{OHC}$ cytosol via a patch pipette. These two treatments appear to interfere with the mechanical response at distinct cellular levels, since only $\mathrm{Gd}^{3+}$ treatment reversibly reduces the voltage-dependent capacitance of the $\mathrm{OHC}$ membrane.

Prcliminary accounts of this work have been reported (SantosSacchi, 1989a, 1990a,b).

\section{Materials and Methods}

General. Guinea pigs were anesthetized with pentobarbital and decapitated. The temporal bones were removed, and the sensory and supporting cells were isolated from the cochleas by gentle pipetting of the isolated top two turns of the organ of Corti. No enzymatic digestion was cmployed for isolation of OHCs or Deiters cells; however, Hensen cells were isolated using trypsin (Santos-Sacchi, 1991). The cell-enriched supernatant was then transferred to a $700 \mu \mathrm{l}$ perfusion chamber, and cells were permitted to settle onto the coverglass bottom. All experiments were performed at room temperature $\left(\sim 23^{\circ} \mathrm{C}\right)$. A Nikon Diaphot inverted microscope with Hoffmann optics was used to observe the cells during electrical recording. All experiments were taped with a Panasonic AG6300 video recorder. A modified Leibovitz medium $(\mathrm{NaCl}, 142.2$ $\mathrm{mm} ; \mathrm{KCl}, 5.37 \mathrm{~mm} ; \mathrm{CaCl}_{2}, 1.25 \mathrm{~mm} ; \mathrm{MgCl}_{2}, 1.48 \mathrm{~mm}$; HEPES, $5.0 \mathrm{~mm}$; dextrose, $5.0 \mathrm{~mm}$; pH 7.2) was used as the normal perfusate. Modifications to the extracellular medium are noted in figure captions, with $\mathrm{NaCl}$ adjusted to maintain osmolarity $(300 \mathrm{mOsm})$. Extracellular solutions were changed via two methods. The chamber perfusion system permits the fluid in the whole chamber to be constantly exchanged with fresh medium $(0.1-1 \mathrm{ml} / \mathrm{min})$ and can bc used to change to solutions of different ionic makeup. A more rapid and direct perfusion system was used to perfuse single cells selectively under voltage clamp, during continuous exchange of bulk medium via chamber perfusion. The device is a two- or four-barreled glass pipette tapered to about $100 \mu \mathrm{m}$ and fitted with a polyethylene sleeve at the tip to permit fluid flow from a single port with a small dead volume. Solutions are fed to the pipette under gravity control and are rapidly switched with solenoid valves. The tip of the pipette is brought to within $50 \mu \mathrm{m}$ of the cell being studied, and the flow of solution is adjusted so as not to perturb the cell physically.

Voltage step studies were performed with an Axolab $1100 \mathrm{~A} / \mathrm{D}$ and D/A board (Axon Instruments, Foster City, CA) with associated software (pCLAMP). AC studies were performed using a digital signal processing board with custom-written software (DSP-16; Ariel Corp., Highland Park, NJ) capable of delivering and analyzing pure tone or swept frequency stimuli. Filtered current records were saved to disk for offline analysis.

Patch electrodes (flint or borosilicate glass) had initial resistances of 3-6 M $\Omega$. The series resistance, that is, the actual electrode resistance obtained upon establishment of whole-cell configuration, typically ranged from 6 to $14 \mathrm{M} \Omega$; for the collection of gating currents and short-duration mechanical events, care was taken to maintain low series resistance values during recording by delivering transient positive or negative pressure into the electrode to maintain an unobstructed orifice. The resistance values were estimated from current transients initiated at the onset of voltage pulses and were corrected for during analysis, so that actual voltages imposed upon the cell are known (Marty and Neher, 1983). The program CLAMPEX (Axon Instruments) was modified to provide a continuous display of clamp time constant, cell capacitance $\left(C_{m}\right)$ and resistance $\left(R_{m}\right)$, and series resistance $\left(R_{s}\right)$ between data collections. Pipette solutions were composed of $140 \mathrm{mM} \mathrm{KCl}$ or CsCl, 5 or $10 \mathrm{~mm}$ EGTA, $2 \mathrm{~mm} \mathrm{MgCl}_{2}$, and $5 \mathrm{~mm}$ HEPES buffered to $\mathrm{pH} 7.2$. In some cases, EGTA was not used. Gigohm seals were obtained at the nuclear level of the cell membrane, and electrode capacitance was compensated prior to whole-cell recording. Generally, single cells were clamped to holding potentials near -70 to $-80 \mathrm{mV}$ using a Dagan patch-clamp amplifier. Hyperpolarizing and depolarizing voltage steps, 5-500 msec in length, were used to elicit membrane currents (filtered at $10 \mathrm{kHz}$ ) and, in the case of OHCs, mechanical movements.

Measurement of $\mathrm{OHC}$ voltage-dependent capacitance. In response to membrane potential perturbations induced by voltage-clamp stimuli, ionic and capacitive membrane currents are normally generated. In order to permit the study of capacitive currents in isolation, $\mathrm{OHC}$ ionic currents were blocked. Typically, patch electrodes contained $140 \mathrm{~mm}$ $\mathrm{CsCl}$, and extracellular solutions contained $20 \mathrm{~mm}$ tetraethylammonium (TEA), $20 \mathrm{~mm} \mathrm{CsCl}$, and 2 mм $\mathrm{CuCl}_{2}$ (see figure captions for modifications). These ionic substitutions were used to block outward and inward $\mathrm{K}^{+}$currents and $\mathrm{Ca}^{2+}$ currents. Although hair cells possess no fast inward sodium currents (however, see Evans and Fuchs, 1987), in some experiments TTX was used in an attempt to reduce residual leakage currents. No apparent effects were noted in those cases.

Step analysis. The aim of the following voltage step protocols was to extract nonlinear charge movement from total charge movement by subtracting out that component due to the linear dielectric properties of the membrane. $\mathrm{OHC}$ gating currents (nonlinear capacitive currents) were measured by averaging current responses elicited by voltage pulses ( $5 \mathrm{msec}$ ) of alternating polarity $(40 \mathrm{mV}$ magnitude) about the holding potential of $-80 \mathrm{mV}$ ( $\pm \mathrm{P}$ technique;' Armstrong and Bezanilla, 1973). Under certain conditions, this technique may not adequately measure nonlinear charge movement. That is, the amount of charge movement produced for opposite-polarity pulses depends upon where the holding potential lies along the actual nonlinear $\mathrm{Q}-\mathrm{V}$ function. Thus, at holding potentials well within this function, the capacitive current induced by a hyperpolarizing pulse is not solely linear, and this technique will result in measurement inaccuracies (see Bezanilla and Armstrong, 1977). In the present study, this technique was only used to evaluate relative changes in nonlinear charge movement at a fixed holding potential. In order to evaluate the voltage dependency of nonlinear charge movement, the following protocols were used to overcome the problems inherent in the $\pm P$ technique.

Detailed measures of voltage versus charge movement were obtained by using a $\mathrm{P} /-4$ protocol (Bezanilla and Armstrong, 1977) at a holding and subtraction potential of $-120 \mathrm{mV}$. This technique derives nonlinear charge movement from total charge movement by subtracting estimates of linear charge movement obtained at a membrane potential where nonlinear components are small or absent. The procedure entails the presentation of four subpulses of a magnitude equal to $\mathrm{P} /-4$; the generated capacitive currents of these subpulses are summed and added to those generated by the depolarizing pulse, $P$. The highly negative holding potential should provide subtraction currents that will more accurately permit measures of nonlinear charge movement for a range of step potentials. Alternatively, linear charge movement was estimated with $5 \mathrm{mV}$ hyperpolarizing pulses at a holding potential of $-120 \mathrm{mV}$, scaled, and subtracted from total charge movement measured in response to a range of depolarizing voltage steps. Voltage-dependent nonlinear charge $\left[Q_{(v)}\right]$ was fit to a Boltzmann function (see Fig. $6 \mathrm{~A}$ and top of Fig. $10 \mathrm{~A}, B$ ):

$$
Q_{(v)}=\left(\frac{Q_{\max }}{1+\exp \left[-z e\left(V-V_{h}\right) / k T\right]}\right)+Q_{\text {min }},
$$

where $V$ is the potential of the step corrected for series resistance using non-leakage-subtracted steady state current levels at the end of the step, $V_{h}$ is voltage at half-maximal charge movement, $e$ is electron charge, $k$

\footnotetext{
'For a nonlinear voltage-dependent charge movement that occurs only upon depolarization from a given holding potential, the summation of capacitive currents induced by opposite polarity steps about the holding potential will result in the extraction of nonlinear capacitive currents. That is, the linear capacitive current produced by the hyperpolarizing step is used to subtract out the linear component induced by the depolarizing step, and only the nonlinear charge movement remains.
} 


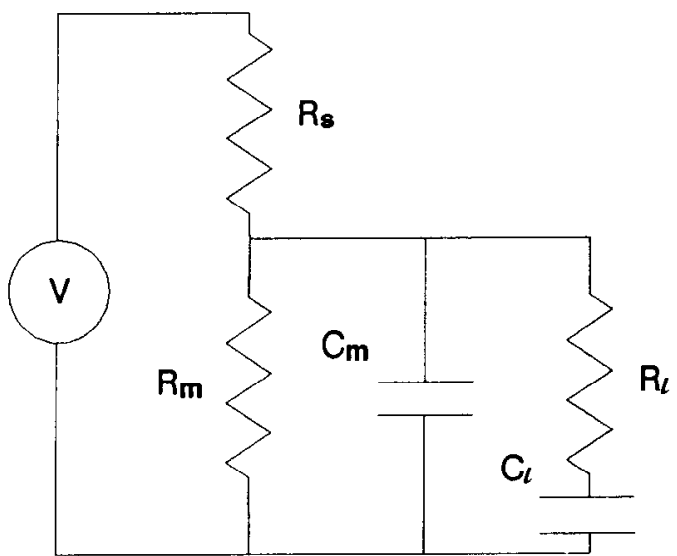

Figure 1. Cell-electrode model. See Materials and Methods for description.

is Boltzmann's constant, $T$ is absolute temperature, $z$ is the valence, $Q_{\max }$ is maximum charge transfer, and $Q_{\min }$ is minimum charge transfer (an offset included to account for possible nonlinear charge movement at levels more hyperpolarized than the subtraction holding potential). Since capacitance, in this case voltage-dependent $\left[C_{(v)}\right]$, is defined as the first derivative of charge with respect to voltage,

$$
C_{(v)}=\frac{d Q_{(v)}}{d v}
$$

estimates of voltage-dependent capacitance were obtained by differentiation of the Boltzmann fits of nonlinear charge movement (see Fig. 6B).

$A C$ analysis. $\mathrm{AC}$ analyses of the voltage-dependent capacitance were also made using the Ariel DSP board, with sampling at $12 \mathrm{kHz}$. OHCs were ramped to hyperpolarized and depolarized potentials from a holding potential of $-80 \mathrm{mV}$, and after $0.2 \mathrm{sec}$, continuous swept frequency stimuli of constant voltage ( $3.53 \mathrm{mV}$ RMS) were delivered; filtered current responses and input voltage $(6 \mathrm{kHz}$, eight pole Bessel; averaged $20 \times$ ) were saved to disk. The first two collections were discarded prior to avcraging. Ccll capacitance was evaluated using impedance data similar to techniques used by others (Fishman et al., 1977; Takashima, 1978; Fernández et al., 1982); however, estimates were made using measures of capacitive reactance $\left(X_{c}\right)$ obtained from the impedance calculations. The real and imaginary components of the impedance were obtained by Fast Fourier transform (FFT) using the software package MATLAB (Mathworks, Natick, MA).

A model often used to analyze whole-cell voltage-clamp data is composed of an electrode resistance (series resistance, $R_{\mathrm{r}}$ ) in series with a parallel combination of a membrane resistance $\left(R_{m}\right)$ and a membrane capacitance $\left(C_{m}\right)$ (Ogden and Stanfield, 1987; see model schematic in Santos-Sacchi, $1989 \mathrm{c})$. The capacitive reactance $(X)$ of such an RCdominated system can be described as a bell-shaped function of frequency (using a linear-log plot), whose characteristic frequency is dependent upon the ccll membrane's RC time constant (see Schanne and Ruiz P.-Ceretti, 1978, their Appendix 2). It is a function in which the effects of $R_{s}$ are absent:

$$
X_{c}=\frac{\omega C_{m} R_{m}^{2}}{1+\omega^{2} C_{m}^{2} R_{m}^{2}}, \quad \omega=2 \pi f
$$

It is useful to avoid the effects of series resistance during the fitting of the experimental data to the model, because series resistance is difficult to measure precisely and can influence the analysis of impedance data (Fernández et al., 1982; Salzberg and Bezanilla, 1983). Unfortunatcly, the simple model of Equation 3 cannot account for the frequencydependent nature of membrane capacitance observed in cells possessing nonlinear charge movement. For example, in the squid axon, Fernández et al. (1982) required an additional single or double time constant factor, modeled as lossy capacitors in parallel with the membrane capacitance. ${ }^{2}$

\footnotetext{
${ }^{2}$ The physical correlates of this model are not easily made. However, the lossy capacitance (series combination of resistance and capacitance) may be viewed as
}

In the present study, fits of experimentally measured $X_{c}$ to that of clamp-cell models were made using the Nelder-Mead simplex algorithm for frequencies between 0.1 and $3 \mathrm{kHz}$, across a range of holding potentials. The characteristic frequency of the OHC's $X_{c}$ is well below 100 $\mathrm{Hz}$ because the cell's time constant under the experimental conditions is quite large; for example, Santos-Sacchi (1989c) determined the OHC time constant at $-70 \mathrm{mV}$ to be about $3.5 \mathrm{msec}(45 \mathrm{~Hz}$ ). Actually, the characteristic frequency will change as a function of holding potential and ultimately depends upon changes of input capacitance (due to voltage-dependent capacitance) and input resistance (due to unblocked nonlinear leakage currents). Fits of the measured $X_{c}$ at various holding potentials were made to determine the model's component values. Goodness of fit was estimated from the square root of the sum of squared residuals: the smaller the value, the better the fit. Fits of OHC $X_{i}$ with the simple RC model of Equation 3 (illustrated in Santos-Sacchi, 1989c) did demonstrate voltage-dependent capacitance, but the goodness of fit was poorer than that obtained with the model of Figure 1, which incorporates an additional lossy capacitance (described below). For an example, see the caption of Figure 7 where the results of fitting the data to both models are presented. While at very negative potentials (e.g., $-136 \mathrm{mV}$ ) both models yield similarly good fits, at depolarized potentials, where voltage-dependent capacitance is substantial, the model of Figure 1 fits the data points more accurately. Therefore, for the analysis of the AC data, the input impedance of the $O H C$ in series with the electrode resistance $\left(R_{s}\right)$ was modeled as a membrane resistance $\left(R_{m}\right)$ and capacitance $\left(C_{m}\right)$ in parallel with a lossy dielectric consisting of a series combination of another capacitance $\left(C_{c}\right)$ and resistance $\left(R_{t}\right)$ :

$Z_{\text {in }}$

$$
\begin{aligned}
& =\left(R_{s}+R_{\text {real }}\right)-j X_{c} \\
& =R_{s}+\frac{R_{m}\left(R_{t}+1 / s C_{c}\right)}{\left(1+s C_{m} R_{m}\right)\left(R_{c}+1 / s C_{c}+R_{m} /\left(1+s C_{m} R_{m}\right)\right)},
\end{aligned}
$$

where $s=j \omega$ and $j=\sqrt{-1}$. The model's capacitive reactance $\left(X_{c}\right)$ is given as

$X_{c}$

$$
\begin{aligned}
& =-\operatorname{imag}\left(Z_{\text {in }}\right) \\
& =\frac{R_{m} \omega\left(\tau_{m}+\tau_{\text {im }}+\tau_{m} \tau_{t}{ }^{2} \omega^{2}\right)}{1+\omega^{2}\left(\tau_{m}{ }^{2}+\tau_{t}^{2}+2 \tau_{m} \tau_{\iota m}+2 \tau_{\iota} \tau_{\iota m}+\tau_{\iota m}{ }^{2}\right)+\tau_{m}{ }^{2} \tau_{t}^{2} \omega^{4}},
\end{aligned}
$$

where $\tau_{t}=R_{t} C_{t}, \tau_{\iota m}=R_{m} C_{\iota}$, and $\tau_{m}=R_{m} C_{m}$.

Although the capacitive reactance is independent of $R_{s}$, all other components $\left(R_{m}, C_{m}, R_{t}\right.$, and $\left.C_{l}\right)$ contribute. Thus, by fitting $\mathrm{OHC} X_{t}$ with the parameters of the model, an estimate of the cell's total capacitance can be obtained $\left(C_{\text {tot }}=C_{m}|| C_{t}\right.$, the parallel combination of the component capacitances; Chandler et al., 1976).

The total capacitance of the $\mathrm{OHC}\left(C_{\text {tot }}\right)$ at any given holding potential is the sum of the linear, non-voltage-dependent, capacitance $\left(C_{\text {lin }}\right)$ and voltage-dependent capacitance $\left(C_{(v)}\right)$ :

$$
C_{\text {tot }}=C_{(v)}+C_{\text {lit }}
$$

Estimates of linear and voltage-dependent capacitance were made by fitting $C_{\text {tot }}$ to Equation 8, with $C_{(v)}$ defined as the first derivative of a Boltzmann function relating charge movement and voltage (see Fig. 8 and bottom of Fig. 10A,B):

$C_{(1)}=\left\{\frac{\left(Q_{\max } z e / k T\right)}{\exp \left[(z e / k T)\left\{V-V_{h}\right\}\right]\left[1+\exp \left[(-z e / k T)\left\{V-V_{h}\right\}\right]\right]^{2}}\right\}$

Measurement of $\mathrm{OHC}$ movement. Movements of the $\mathrm{OHCs}$ were analyzed by three methods. For steady state movements (voltage steps $>100 \mathrm{msec}$ ), length changes were analyzed off the video monitor during playback either by direct measurement off the video monitor using single still frames (Santos-Sacchi and Dilger, 1988) or by placing differential optoresistors or a position-sensitive detector (PSD; Hamamatsu Corp., Bridgewater, NJ) (output filtered at $30 \mathrm{~Hz}$ ) across the image of the cuticular plate at a monitor magnification of $2800 \times$. The linearity of

the voltage-dependent capacitive component, and the frequency dependence it imparts to the model may correspond to the time-dependent nature of nonlinear charge movement within the membrane (see Fernández et al., 1982). 


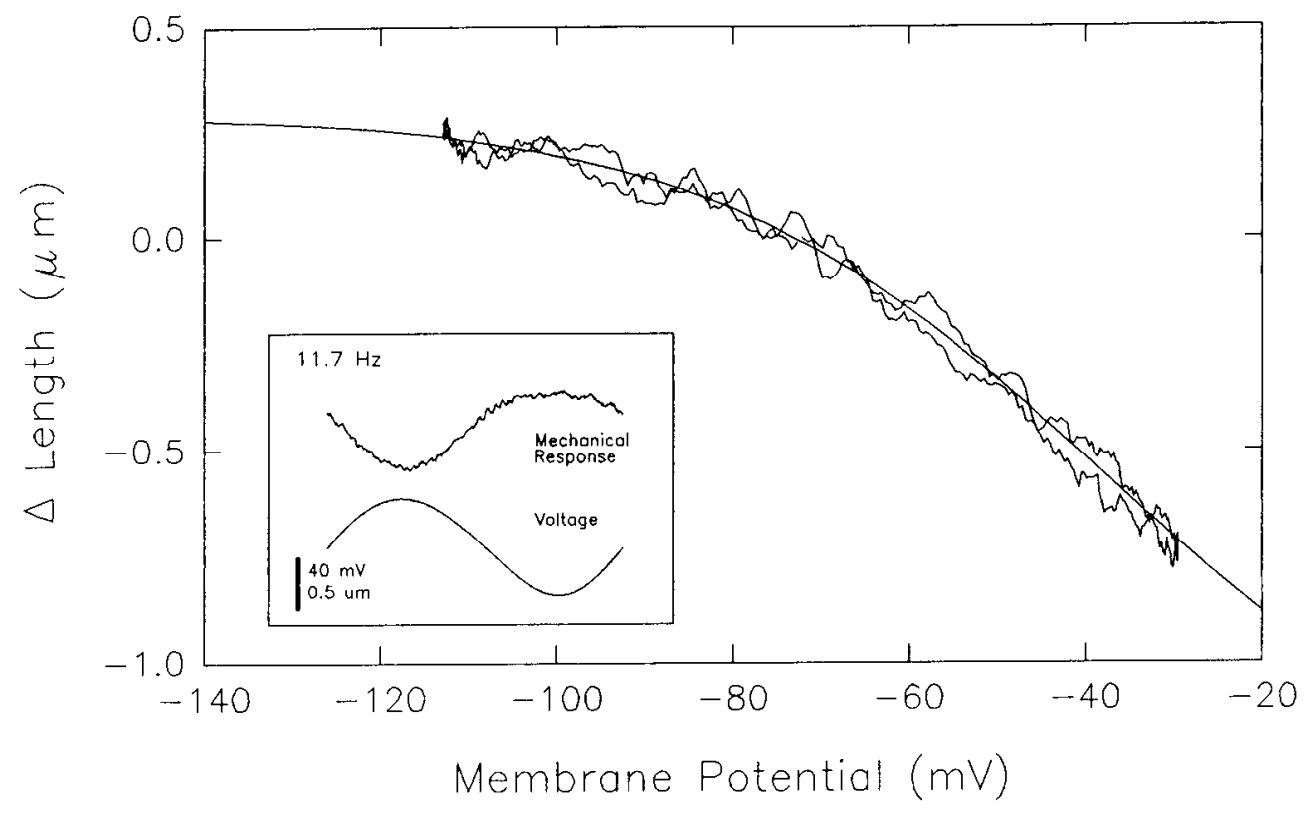

Figure 2. The voltage-displacement response of an $\mathrm{OHC}$ to an $11.7 \mathrm{~Hz}$ sinusoidal voltage stimulus superimposed upon a holding potential of about $-74 \mathrm{mV}$, as measured with the differential photodiode technique. Solid smooth line is fit to a Boltzmann function with $V_{h}$ at $-38 \mathrm{mV}$ and $z=1.14$. Inset, Movement and voltage waveforms. Series resistancc-corrected voltage trace was derived from the simultaneously recorded whole-cell current record by modeling the cell-clamp setup as a simple $R_{m} C_{m}$ cell circuit in series with the electrode's series resistance (Santos-Sacchi, 1989c), the values of which were estimated from responses to voltage steps. Current was transformed into the frequency domain by FFT and the voltage was calculated using the component values and converted into the time domain by reverse Fourier transform. Extracellular medium contained $20 \mathrm{~mm}$ TEA, $300 \mathrm{~nm}$ TTX, and no added $\mathrm{Ca}^{2+} . \mathrm{CsCl}$ pipette solution. the optoresistor method was confirmed by measuring the videotaped movement of the tip of a microelectrode driven by a piezoelectric bimorph element (Santos-Sacchi, 1989c). Fast OHC movements elicited by voltage clamp with short-duration stimuli (below video detection) were measured with a differential photodiode onto which the image of the cuticular plate from the microscope was projected. The placement and manipulation of the photodiode was accomplished by a computer controlled micromanipulator. The photodiode was backlit by two fiber optic beams projected through the microscope's camera port onto a $30 \%$ mirrored glass coverslip base of the perfusion chamber, and reflected back to a charge coupled device (CCD) video camera via a $90^{\circ}$ prism to allow photodiode placement during simultaneous cell visualization on a mixed video-computer monitor (Matrox Corp., Canada). Backlighting was not required after calibration of the photodiode's position on the monitor. The frequency response of the differential photodiode was flat out to $2 \mathrm{kHz}$ (measured with a light-emitting diode or piezoelectric bimorph). Measures of $\mathrm{OHC}$ movements by the photodioide method were performed by averaging the simultaneously recorded current and photodioide output 200 times, in response to step or pure tone voltage stimuli. Absolute calibration of cell movements was determined by measuring off the video monitor the cell movement in response to a large steady state depolarizing voltage stimulus. The error in absolute measures was estimated to be less than $20 \%$.

\section{Results}

Under voltage clamp, OHCs respond to voltage alterations by changing their length. Figure 2 illustrates the voltage dependence of the magnitude of $\mathrm{OHC}$ cell length changes. At a holding potential near $-75 \mathrm{mV}$, an $11.7 \mathrm{~Hz}$ sinusoidal voltage stimulation of the $\mathrm{OHC}$ induces contraction during the depolarizing phase and elongation during the hyperpolarizing phase. The response is greater in the depolarization direction and corroborates the voltage-mechanical response function obtained by voltage step analysis (Santos-Sacchi, 1989c). The maximum cxcursion for these mechanical responses, at voltage step extremes, can be up to about $3-4 \mu \mathrm{m}$, with slopes in the midregion as great as $30 \mathrm{~nm} / \mathrm{mV}$. The voltage-mechanical response function indicates that at potentials near the resting potential measured in vivo, $-70 \mathrm{mV}$ (Dallos et al., 1982), sinusoidal stimulation will produce asymmetrical mechanical responses, that is, DC mechanical responses in addition to sinusoidal responses (Santos-Sacchi, 1989c). These DC responses are in the depolar- ization-contraction direction and have been observed up to frequencies as high as $3.2 \mathrm{kHz}$ (J. Santos-Sacchi, unpublished observations).

Depolarization of the $\mathrm{OHC}$ elicits outward $\mathrm{K}^{+}$currents, which are blocked to varying degrees by a host of treatments, including intracellular Cs, or extracellular TEA, $\mathrm{Cd}^{2+}, \mathrm{Ba}^{2+}$, charybdotoxin (ChTX), 4-aminopyridine (4-AP), octanol, and $\mathrm{Gd}^{3+}$. Figure $3 A$ illustrates an $I-V$ function and associated current traces for a cell voltage clamped with a pipette containing $\mathrm{KCl}$ solution, before and after treatment with $500 \mu \mathrm{M} \mathrm{Gd}^{3+}$. Outward $\mathrm{K}^{+}$ currents are blocked by $\mathrm{Gd}^{3+}$; however, unlike other ionic blockers, $\mathrm{Gd}^{3+}$ treatment reduces or abolishes the $\mathrm{OHC}$ mechanical responses elicited by depolarizations. This can be seen in the simultaneously measured mechanical responses of this cell; mechanical responses were undetectable after $\mathrm{Gd}^{3+}$ treatment (Fig. 3A).

OHC mechanical responses are rapid in onset following a voltage stimulus, with the onset time constant principally determined by the speed of the voltage clamp (Santos-Sacchi, $1990 \mathrm{a})$. Figure $3 B$ depicts the response of an OHC to voltage steps of 5 msec duration. Treatment of this cell with $1 \mathrm{~mm} \mathrm{Gd}^{3+}$ caused a developing block of motility (traces a-d). In this case, about $5 \mathrm{~min}$ after the start of $\mathrm{Gd}^{3+}$ perfusion, the cell contractions stopped. Recovery followed washout. Traces labeled f represent steps from $-80 \mathrm{mV}$ to $-30,0$, and $+30 \mathrm{mV}$ and illustrate the saturating nonlinearity in the magnitude of response occurring at highly depolarized levels (Santos-Sacchi and Dilger, 1988). The time constant of mechanical response onset changed during the development of $\mathrm{Gd}^{3+}$ block. Since this time constant is critically dependent upon the time constant of the clamp amplifier (Santos-Sacchi, 1990a), it is necessary to determine whether the clamp time constant was altered during the data collections. Simultaneously recorded currents revealed that the clamp time constant actually shortened (from 0.21 to $0.18 \mathrm{msec}$ ) during the collections and thus could not account for the increases of the time constant for mechanical responses $(0.26,0.44$, and 0.57 insec for traces $a-c$, respectively).

The reversibility of the $\mathrm{Gd}^{3+}$ effects upon the $\mathrm{OHC}$ mechan- 
A

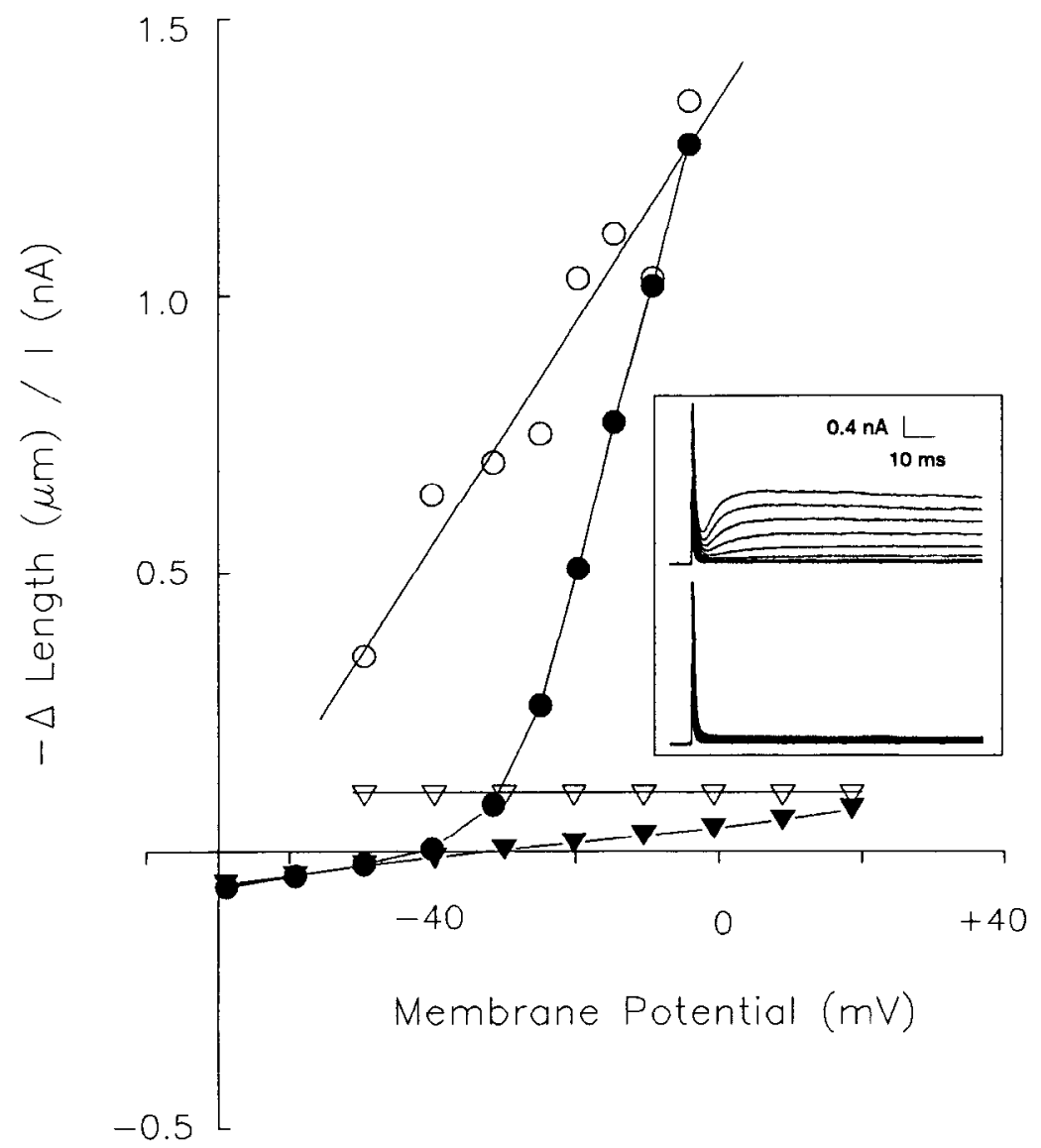

B

a

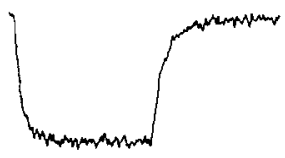

b

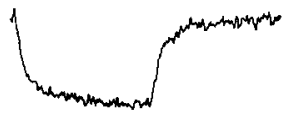

c

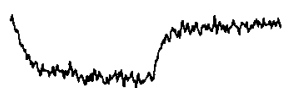

d

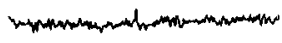

e
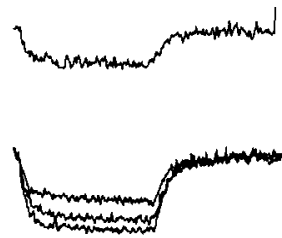

$1.5 \mathrm{um}$

$2.5 \mathrm{~ms}$

C
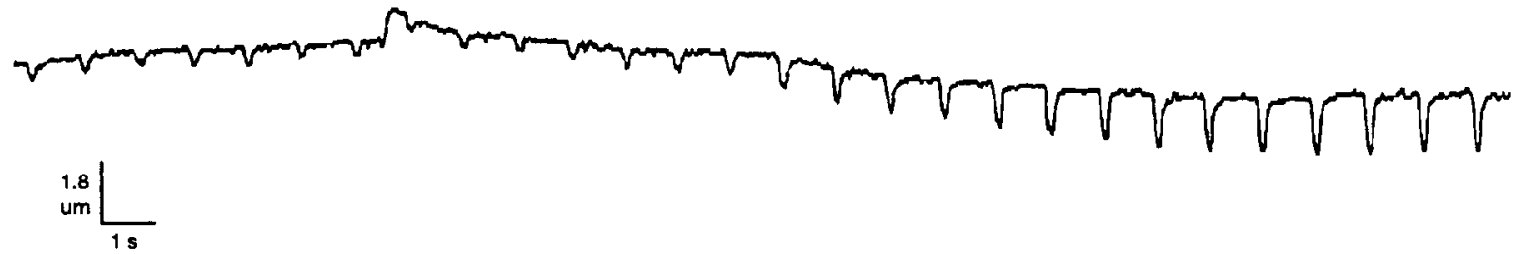

Figure 3. A, Simultaneously recorded whole-cell currents and mechanical responses of an $\mathrm{OHC}$ before and after treatment with $500 \mu \mathrm{M} \mathrm{Gd}^{3+}$. Medium was Leibovitz without added $\mathrm{Ca}^{2+}$. Electrode contained $\mathrm{KCl}$ solution. Solid circles, Currents before $\mathrm{Gd}^{3+}$ treatment; open circles, movements before $\mathrm{Gd}^{3+}$ treatment measured with differential optoresistor from video monitor. Solid triangles, Currents after addition of $\mathrm{Gd}^{3+}$; open triangles, movements undetectable after $\mathrm{Gd}^{3+}$. Vertical scale corresponds to $\mathrm{nA}$ or $\mu \mathrm{m}$ of contraction. Series resistance corrected, no leakage current subtraction. Inset. Current traces before and after $\mathrm{Gd}^{3+}$ treatment. $B$, Mechanical responses of an $\mathrm{OHC}$ to short duration voltage steps from a holding potential of -80 to $40 \mathrm{mV}$ (nominal; $a-e)$ before $(a)$, during $[b(1 \mathrm{~min}), c(2 \mathrm{~min}), d(5 \mathrm{~min})]$, and after [ $e(2 \mathrm{~min}$ wash $)]$ perfusion with $1 \mathrm{~mm} \mathrm{Gd}^{3+}$. Traces labeled $f(7 \mathrm{~min}$ wash $)$ depict mechanical responses to voltages of $-30,0$, and $+30 \mathrm{mV}$. Extracellular medium contained $20 \mathrm{~mm}$ TEA, $20 \mathrm{~mm}$ $\mathrm{CsCl}$, and no added $\mathrm{Ca}^{2+} . \mathrm{CsCl}$ pipette solution. $C$, Reversibility of $\mathrm{Gd}^{3+}$ effects upon mechanical response. OHC was directly perfused with 500 $\mu \mathrm{M} \mathrm{Gd}{ }^{3+}$ in Ca-free Leibovitz, as indicated. Upon washout of the trivalent cation, the mechanical response increases over time. Contraction of the cell is indicated by the downward deflections of the trace measured with differential optoresistor from video monitor. 


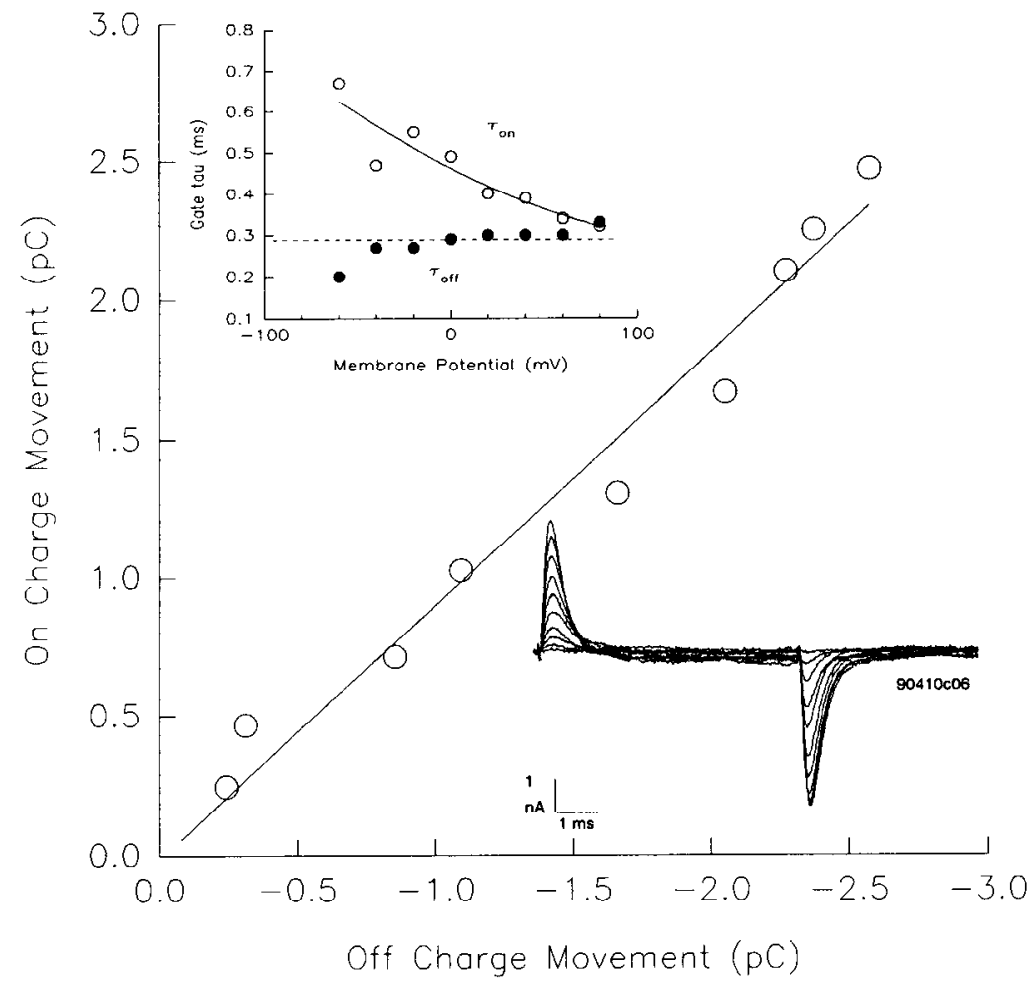

B

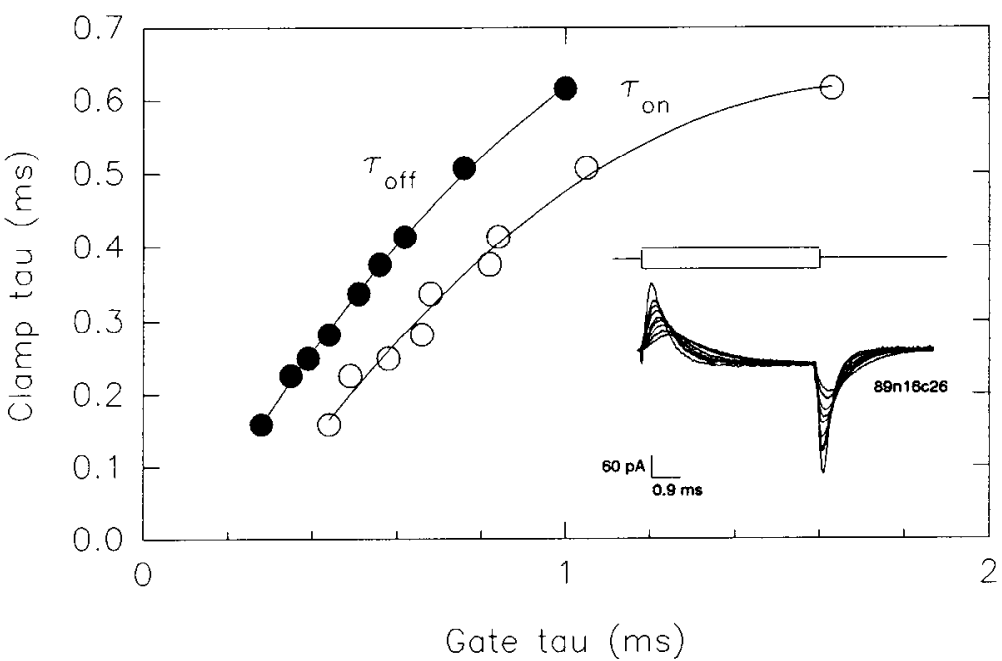

Figure 4. $A, \mathrm{OHC}$ on-charge versus off-charge measured by integrating onand off-gating currents over time as a function of voltage step size. Trace inset depicts nonlinear capacitive currents obtained by $\mathrm{P} /-4$ procedure at a holding and subtracting potential of -120 $\mathrm{mV}$. Step depolarizations were in 20 $\mathrm{mV}$ increments up to $80 \mathrm{mV}$. Line is least-squares linear fit, indicating roughly equal nonlinear charge movements at onset and offset of voltage pulses. Inset, Single exponential time constant of current decay for on and off currents as a function of step potential. Broken line indicates clamp time constant. Open circles, $\tau_{\text {on }}$; solid circles, $\tau_{\text {off }}$. Cell perfused with Leibovitz containing $20 \mathrm{~mm}$ TEA, $20 \mathrm{~mm} \mathrm{CsCl}$, and $2 \mathrm{~mm}$ $\mathrm{CoCl}_{2} . \mathrm{CsCl}$ electrode. $B$, Dependence of OHC gating current time constants upon clamp time constant. Procedure was $\pm P(40 \mathrm{mV})$ at a holding potential of $-80 \mathrm{mV}$. Traces depict nine individual collections (averaged $200 \times$ ) with different clamp time constants. The time constant of the clamp is dependent upon the series resistance of the patch electrode (Ogden and Stanfield, 1987) and was modified by electronically compensating the series resistance through feedback controls on the amplifier. Open circles, $\tau_{\text {on }}$; solid circles, $\tau_{\text {orf }}$. Cell perfused with $20 \mathrm{~mm}$ TEA Leibovitz. $\mathrm{CsCl}$ electrode. ical response is more clearly demonstrated in Figure $3 C$. This cell was continuously stepped to a voltage of $0 \mathrm{mV}$ from a holding potential near $-80 \mathrm{mV}$. While the cell was in the presence of $500 \mu \mathrm{M} \mathrm{Gd}{ }^{3+}$, mechanical responses were barely detectable; however, changeover to wash medium quickly initiated a recovery from the trivalent cation's effects. The block of ionic conductances is also rapidly reversible. Interestingly, washout with medium containing $500 \mu \mathrm{M} \mathrm{Cd}^{2+}$ did not restore motility. It is important to note that the block of OHC longitudinal motility by gadolinium ions was not due to or associated with a loss of cell turgor (see below). However, gadolinium produced a lengthening of the $\mathrm{OHC}$, sometimes up to several micrometers.
The shapes of supporting cells were not affected by similar treatments. Typically, concentrations of about $500 \mu \mathrm{M}$ were required to interfere with the magnitude of mechanical response. On the other hand, OHC outward currents were rcadily blocked, and under current clamp, membrane potentials were reversibly depolarized at concentrations as low as $50 \mu \mathrm{M}$. Low concentrations of $\mathrm{Gd}^{3+}$ similarly affected ionic currents of supporting Deiters cells.

OHCs exhibit a nonlinear capacitive (gating) current that is directed outward at the onset of a voltage depolarization and inward during the repolarization. Such gating currents are readily observed after blocking ionic currents (Fig. $4 A$, trace inset). 


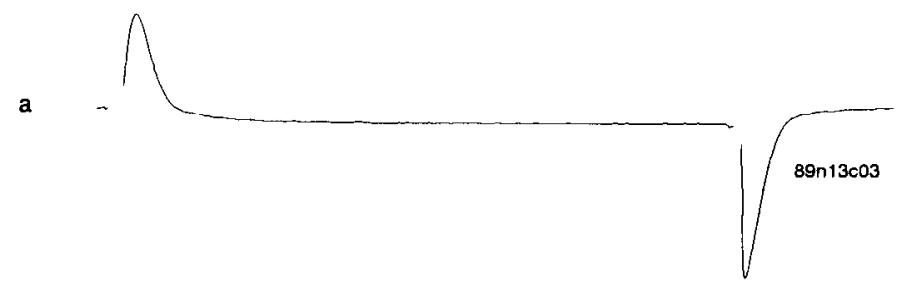

b

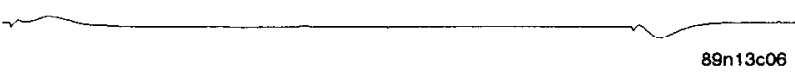

c
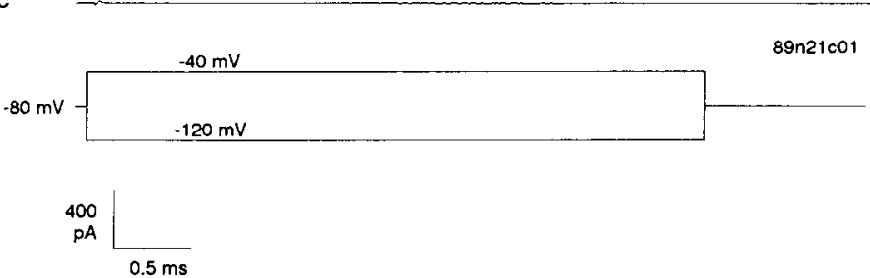

Figure 5. Block of $\mathrm{OHC}$ nonlinear charge movement by gadolinium ions. Bottom trace indicates voltage protocol of the $\pm \mathbf{P}$ technique used to obtain the current traces (see Materials and Methods). $a$, Gating currents of $\mathrm{OHC}$ measured with the $\pm P$ technique; $10 \mathrm{~mm}$ TEA, 300 nм TTX Leibovitz. $\mathrm{CsCl}$ electrode. $b$, Same cell after treatment with

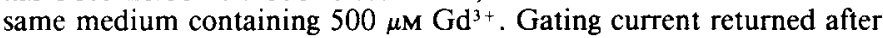
washout. $c$, Absence of gating currents in Deiters cell; $20 \mathrm{~mm}$ TEA Leibovitz. $\mathrm{CsCl}$ electrode.
Charge transfer at voltage step onset and offset is cssentially equal (Fig. 4). In cells where nonlinear leakage currents were small it was possible to look at the time constant of decay of the on-gate current. Whereas the time constant for the off-gate current was not voltage dependent, that of the on-gate was voltage dependent, decreasing with increasing depolarization step size until it approached both off-gate and clamp time constant values (Fig. $4 A$, inset); however, it was impossible to study this relationship validly because both gate time constants were dependent upon the time constant of the voltage clamp. Figure $4 B$ clearly demonstrates this dependence and indicates that charge movement across the membrane is redistributed in time as a function of clamp time constant.

Figure 5 illustrates the effect of $\mathrm{Gd}^{3+}$ treatment on $\mathrm{OHC}$ gating current measured at $-80 \mathrm{mV}$ with the $\pm P$ technique. In this case, $500 \mu \mathrm{M} \mathrm{Gd}^{3+}$ nearly abclishes the current (Fig. 5 b); the current can recover during washout of $\mathrm{Gd}^{3+}$. Supporting cells do not demonstrate a nonlinear capacitive current under the same conditions (Fig. 5c). A more detailed analysis of the effects of $\mathrm{Gd}^{3+}$ on $\mathrm{OHC}$ nonlinear charge movement follows.

$\mathrm{OHC}$ nonlinear charge movement displays a saturating magnitude-voltage relation (Fig. $6 \mathrm{~A}$, solid circles). A Boltzmann fit to the data (solid line) indicates that the voltage $\left(V_{h}\right)$ for halfmaximal charge movement is $-23.8 \mathrm{mV}$, with a valence $(z)$ of 0.87 . Maximum charge transfer up to about $2.5 \mathrm{pC}$ has been observed in OHCs from the apical portion of the cochlea using the $\mathrm{P} /-4$ technique at a holding and subtraction potential of $-120 \mathrm{mV}$. Differentiating the Boltzmann fit (Fig. $6 \mathrm{~B}$, solid line marked with solid circle) indicates a peak nonlinear voltagedependent capacitance of about $17 \mathrm{pF}$. Gadolinium ions shift
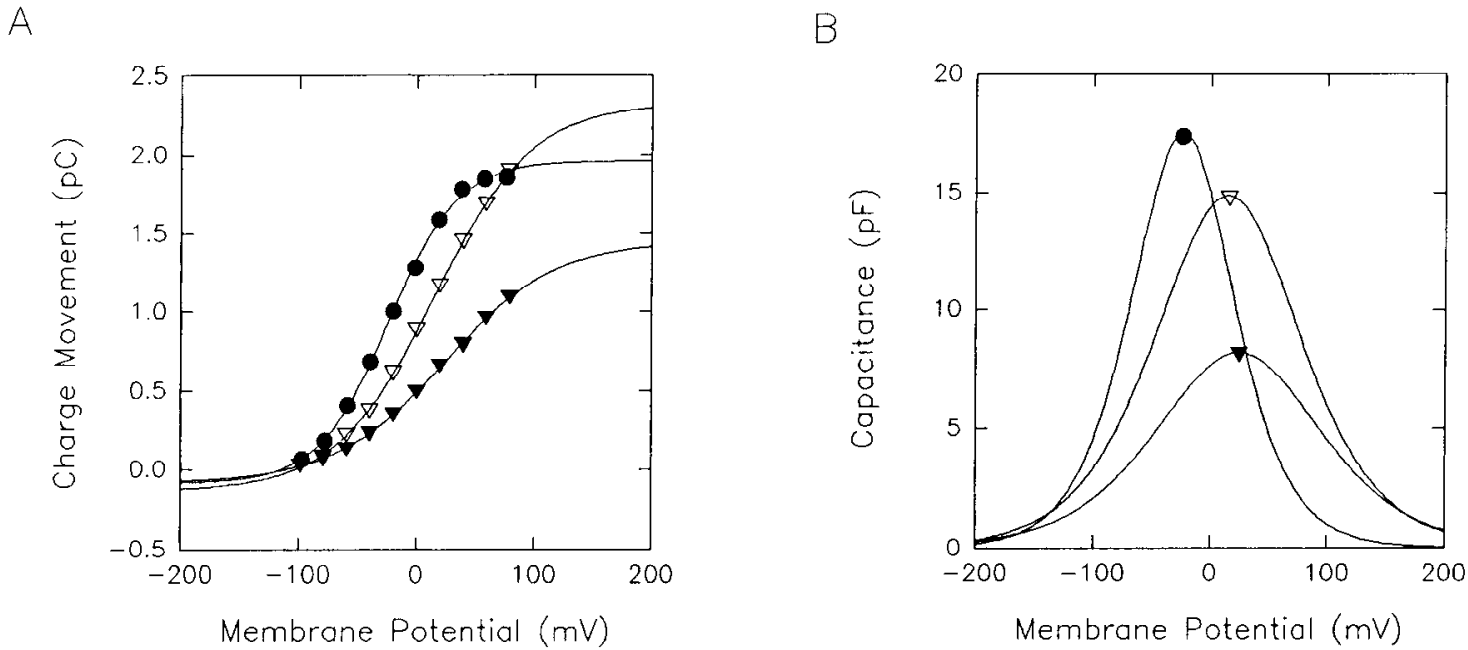

Figure 6. Average nonlinear charge movement and capacitance versus step potential corrected for series resistance determined using the $\mathrm{P} /-4$ technique. On-charge and off-charge were averaged. Cells were held at $-120 \mathrm{mV}$ and stepped in $20 \mathrm{mV}$ increments to a maximum of $80 \mathrm{mV}$ (nominal voltages; see Materials and Methods). A, Solid circles, Average of four cells. Solid line is the fit to Equation $1 . V_{h}$ and $z:-23.8 \mathrm{mV}$ and 0.87 , respectively. Bath perfusion contained $20 \mathrm{~mm} \mathrm{TEA}, 20 \mathrm{mM} \mathrm{CsCl}, 2 \mathrm{~mm} \mathrm{CoCl}$, and no added $\mathrm{Ca}^{2+}$. No direct cell perfusion. CsCl electrode, no EGTA. Open triangles, Average of four different cells. Solid line is the fit to Equation $1 . V_{h}$ and $z: 14.8 \mathrm{mV}$ and 0.62 , respectively. Cells were individually perfused with $20 \mathrm{~mm}$ TEA, $20 \mathrm{~mm} \mathrm{CsCl}, 2 \mathrm{mM} \mathrm{CoCl}_{2}$, and no added $\mathrm{Ca}^{2+}$ medium from one barrel of a double-barreled pipette whose other barrel contained an additional $1 \mathrm{mM} \mathrm{GdCl}_{3}$. Bath perfusion as above. CsCl electrode, no EGTA. Solid triangles, Average of same four cells as depicted by open triangles. Solid line is the fit to Equation $1 . V_{h}$ and $z: 24.1 \mathrm{mV}$ and 0.55 , respectively. Cells were individually perfused from barrel containing $20 \mathrm{~mm}$ TEA, $20 \mathrm{mM} \mathrm{CsCl}, 2 \mathrm{~mm} \mathrm{CoCl}, 1 \mathrm{mM} \mathrm{GdCl}_{3}$, and no added $\mathrm{Ca}^{2+}$ medium. Bath perfusion as above. CsCl electrode, no EGTA. $B$, Voltage-dependent capacitance of cells in $A$ as determined from first derivative of fitted charge movement with respect to voltage Symbol-marked curves correspond to fits in $A$. Note, in addition to apparent charge screening by gadolinium, the reduction of voltage-dependent capacitance. 
the voltage dependence and reduce the amount of OHC nonlinear charge movement. Charge movements represented by the open triangles in Figure $6 A$ were obtained while perfusing an ionic blocking solution (see figure caption) via a double-barreled pipette, the other barrel containing an additional $1 \mathrm{mM} \mathrm{Gd}^{3+}$. The voltage shift relative to the data represented by the solid circles suggests that charge screening ${ }^{3}$ had occurred due to diffusion of $\mathrm{Gd}^{3}$ । from the gadolinium-containing barrel. A Boltzmann fit to these data (solid line) indicates a $V_{h}$ of $14.8 \mathrm{mV}$ and $z$ of 0.62 . Figure $6 B$ indicates that the peak capacitance is about $14 \mathrm{pF}$ (solid line marked with open triangle). Upon perfusion with the $1 \mathrm{mM} \mathrm{Gd}^{3+}$-containing solution, an additional voltage shift is noted and a marked decrease in the charge displacement is observed (solid triangles). The Boltzmann fit (solid line) gives a $V_{h}$ of $24.2 \mathrm{mV}$ and $z$ of 0.55 . Corresponding peak capacitance is about $7.5 \mathrm{pF}$ (Fig. $6 \mathrm{~B}$, solid line marked with solid triangle).

Analysis of the nonlinear charge movement in the frequency domain for the same cells corroborates the time domain analysis. The capacitive reactance of the cells was determined at various holding potentials for frequencies up to $3 \mathrm{kHz}$. These measures were fit with the model of Figure 1 to obtain estimates of linear and nonlinear membrane capacitance. Figure $7 A$ demonstrates that the capacitive reactance $\left(X_{c}\right)$ of the $\mathrm{OHC}$ changes when the holding potential of the cell is changed from -136 to $-18 \mathrm{mV}$. In this case, fitting the data (solid lines; see Materials and Methods) reveals an increase of about $10 \mathrm{pF}$ upon depolarization of the cell to $-18 \mathrm{mV}$. Perfusion of the cell with 1 $\mathrm{mM} \mathrm{Gd}^{3+}$ reduces the nonlinear voltage-dependent capacitance (Fig. $7 B$ ). Since measures of $X_{c}$ reflect the contribution of resistive as well as capacitive elements, frequency-dependent changes in cell capacitance cannot be obtained simply by taking the difference between $X_{c}$ measures obtained at different holding levels. In order to evaluate the frequency dependence of the membrane capacitance, it is necessary to process the impedance data according to the techniques of Fernández et al. (1982). ${ }^{4}$ Figure $7 C$ illustrates the results of such an analysis. The traces depict the voltage-dependent capacitance at selected holding potentials $(-79,-18$, and $+42 \mathrm{mV}$; corrected for series resis-

\footnotetext{
${ }^{3}$ Membrane surface potentials can arise from fixed surface charges. Charge screening refers to the alteration of this surface potential by the application of coor counterions. Since the voltage that a membrane-bound voltage sensor detects will be influenced by the membrane surface potential, the alteration of surface potential by charge screening can shift voltage-dependent membrane processes along the voltage axis (for review, see Hille, 1984).

${ }_{4}^{4}$ The technique involves manipulation of the impedance data, after removal of series resistance effects. Briefly, after subtracting estimates of the series resistance from the input impedance measures and calculating the susceptance $\left(B_{m}\right)$ from the admittance transform $\left(1 / Z_{\text {in }}\right)$, a measure of cell capacitance as a function of frequency $\left(B_{m} / \omega\right)$ can be obtained (for more detailed information, see Fernández et al., 1982)
}

Figure 7. Capacitive reactance of $\mathrm{OHC}$ as determined with $\mathrm{AC}$ analysis (see Materials and Methods). A, Capacitive reactance (points) prior to gadolinium treatment determined at a holding potential of -136 and $-18 \mathrm{mV}$ as indicated in figure. Fitted curves were obtained with Equation 7. Fitted parameters for $-136 \mathrm{mV}$ collection were $R_{m}, 87.2 \mathrm{M} \Omega$; $C_{m}, 29 \mathrm{pF} ; R, 13.4 \mathrm{M} \Omega ; C_{i}, 5.5 \mathrm{pF}$. $C_{\text {tot }}\left(C_{m} \| C_{i}\right), 34.5 \mathrm{pF}$. Goodness of fit (see Materials and Methods), 4.5 M . Fitted parameters for $-18 \mathrm{mV}$ collection were $R_{m}, 132 \mathrm{M} \Omega ; C_{m}, 32.4 \mathrm{pF}, R_{i}, 11.4 \mathrm{M} \Omega ; C_{t}, 11.6 \mathrm{pF} . C_{10}$ $\left(C_{m} \| C_{c}\right), 44 \mathrm{pF}$. Goodness of fit, $1.1 \mathrm{M} \Omega$. Voltage-dependent change in capacitance, $9.5 \mathrm{pF}$. Data were also fitted (not shown) to the simple RC model (Eq. 3) described in Materials and Methods. Fitted parameters for $-136 \mathrm{mV}$ collection were $R_{m}, 82.5 \mathrm{M} \Omega ; C_{m}, 34.2 \mathrm{pF}$. Goodness of fit, $5.2 \mathrm{M} \Omega$. Fitted parameters for $-18 \mathrm{mV}$ collection were $R_{m}, 86.6$
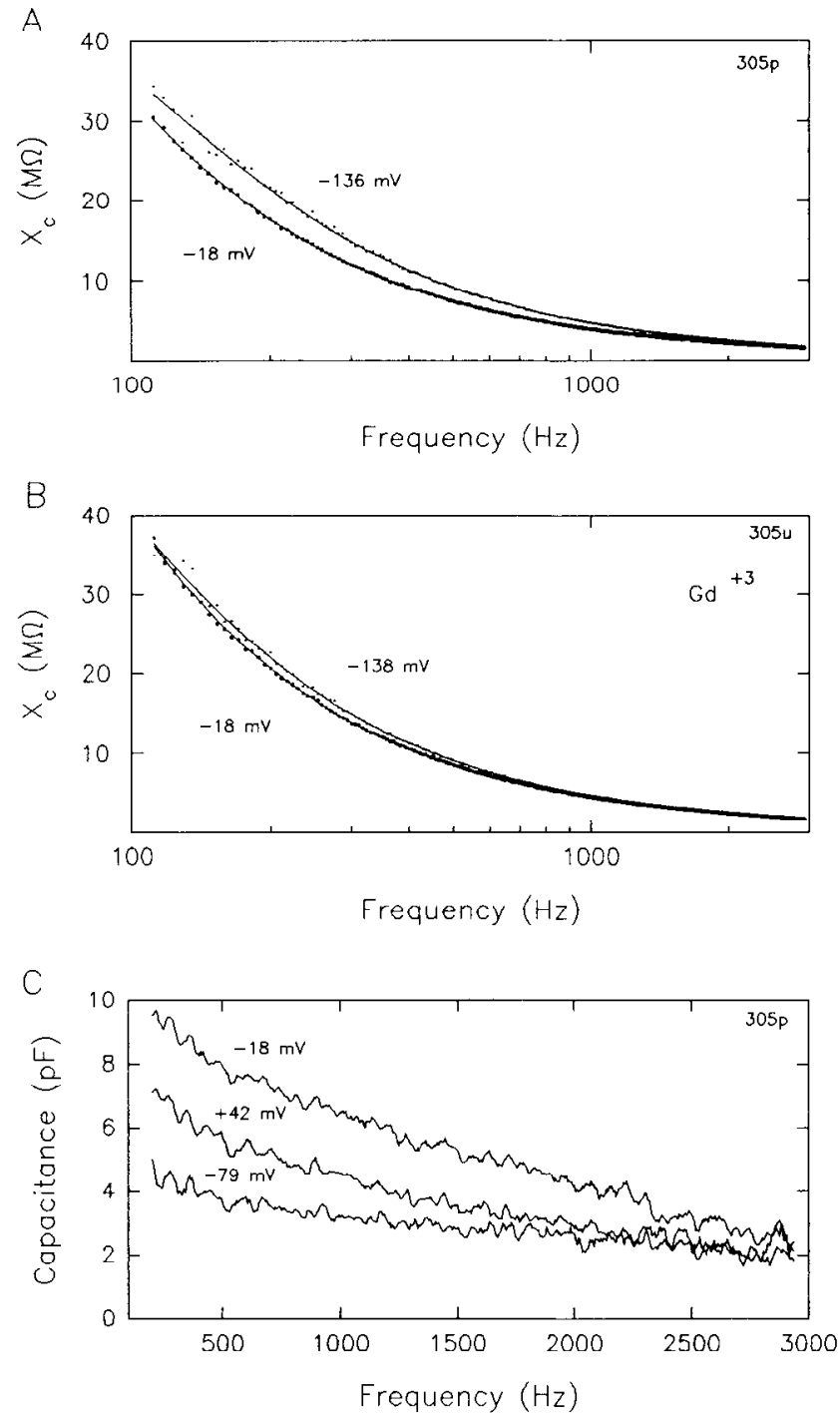

$\mathrm{M} \Omega ; C_{m}, 42.1 \mathrm{pF}$. Goodness of fit, $5.9 \mathrm{M} \Omega$. Voltage-dependent change in capacitance, $7.9 \mathrm{pF}$. Cell was individually perfused with $20 \mathrm{~mm}$ TEA, $20 \mathrm{~mm} \mathrm{CsCl}, 2 \mathrm{mM} \mathrm{CoCl}_{2}$, and no added $\mathrm{Ca}^{2+}$ medium from one barrel of a double-barreled pipette whose other barrel contained an additional $1 \mathrm{~mm} \mathrm{GdCl}$. Bath perfusion as in Figure 6. CsCl electrode, no EGTA. $B$, Capacitivc reactance (points) of same cell after gadolinium treatment determined at a holding potential of -138 and $-18 \mathrm{mV}$ as indicated in figure. Fitted curves were obtained with Equation 7 . Fitted parameters for $-138 \mathrm{mV}$ collection were $R_{m}, 120 \mathrm{M} \Omega ; C_{m}, 29 \mathrm{pF} ; R_{1}, 12.1 \mathrm{M} \Omega ; C_{1}$, $5.95 \mathrm{pF} . C_{\text {tot }}\left(C_{m} \| C_{1}\right), 34.95 \mathrm{pF}$. Goodness of fit, $3.9 \mathrm{M} \Omega$. Fitted parameters for $-18 \mathrm{mV}$ collection were $R_{m}, 236 \mathrm{M} \Omega ; C_{m}, 31.7 \mathrm{pF} ; R_{i}, 21.5$ $\mathrm{M} \Omega ; C_{i}, 6.6 \mathrm{pF} . C_{\text {tot }}\left(C_{m} \| C_{i}\right), 38.3 \mathrm{pF}$. Goodness of fit, $1.8 \mathrm{M} \Omega$. Voltagedependent change in capacitance, $3.3 \mathrm{pF}$. Data were also fitted (not shown) to the simple RC model (Eq. 3) described in Materials and Methods. Fitted parameters for $-136 \mathrm{mV}$ collection were $R_{m}, 109 \mathrm{M} \Omega$; $C_{m}, 34.5 \mathrm{pF}$. Goodness of fit, $5.2 \mathrm{M} \Omega$. Fitted parameters for $-18 \mathrm{mV}$ collection were $R_{m}, 130 \mathrm{M} \Omega ; C_{m}, 37 \mathrm{pF}$. Goodness of fit, $5.9 \mathrm{M} \Omega$. Voltage-dependent change in capacitance, $2.5 \mathrm{pF}$. Cell was individually perfused from barrel containing $20 \mathrm{~mm}$ TEA, $20 \mathrm{~mm} \mathrm{CsCl}, 2 \mathrm{~mm} \mathrm{CoCl}_{2}$, $1 \mathrm{~mm} \mathrm{GdCl}$, and no addcd $\mathrm{Ca}^{3+}$ medium. Bath perfusion as in Figure 6. CsCl electrode, no EGTA. $C$, Membrane capacitance of the $\mathrm{OHC}$ in $A$. The frequency dependence of $\mathrm{OHC}$ membrane capacitance was estimated using the technique of Fernández et al. (1982) (see footnote 4) and plotted using linear axes. Data are plotted after subtraction of the response obtained at $-136 \mathrm{mV}$, and were smoothed using a five-point running average. These plots are a true measure of the real part of the membrane's voltage-dependent complex capacitance, provided that the value used for series resistance subtraction is correct and that minimal voltage-dependent capacitance is present at the subtraction holding potential of $-136 \mathrm{mV}$. 


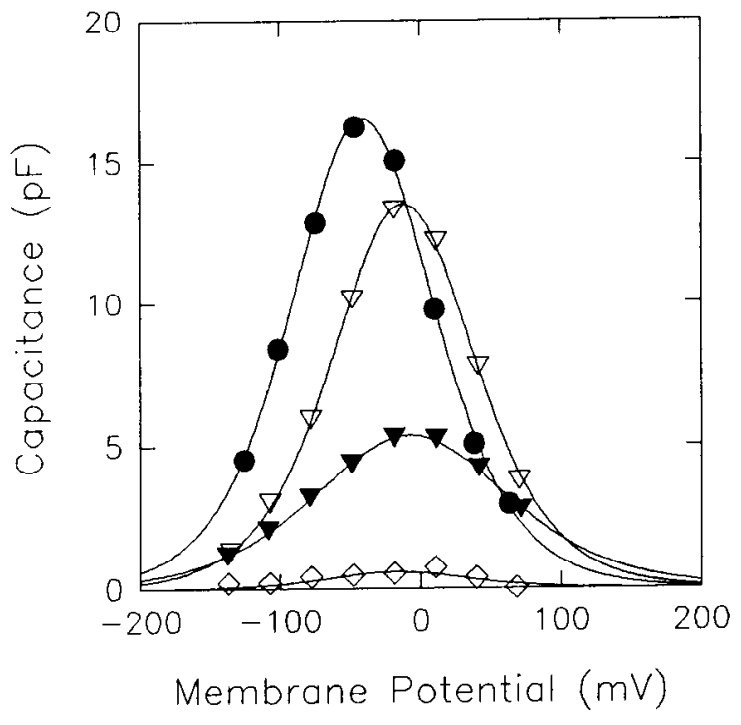

Figure 8. Average voltage-dependent capacitance determined from AC analysis for same cells as in Figure 6. Total capacitance was determined as a function of holding potential as in Figure 7 (see Materials and Methods). Symbols correspond to those of Figure 6. In addition, open diamonds represent average of data obtained from two Deiters cells and two Hensen cells, treated the same as those cells depicted by solid circles (see Fig. 6). Data were fit to Equation 8 to obtain voltagedependent $\left(C_{(\mathrm{r})}\right)$ and non-voltage-dependent $\left(C_{\text {lin }}\right)$ capacitance and were plotted after subtracting $C_{\operatorname{lin}} . C_{\text {tin }}, V_{h}$, and $z$ : solid circles, $23.2 \mathrm{pF},-40.7$ $\mathrm{mV}, 0.76$; open triangles, $29.9 \mathrm{pF},-11.8 \mathrm{mV}, 0.76$; solid triangles, 30.3 $\mathrm{pF},-7 \mathrm{mV}, 0.55$; open diamonds, $30 \mathrm{pF},-16.3 \mathrm{mV}, 0.76$. tance effects) as a function of frequency. The data demonstrate the voltage- and frequency-dependent nature of $\mathrm{OHC}$ membrane capacitance and are similar to the results obtained by Fernández et al. (1982) in the squid giant axon. Unfortunately, the usefulness of this type of analysis depends upon precise measurement of series resistance, since small inaccuracies in the measurement will provide incorrect estimates of the capacitance's frequency dependence. It should he reemphasized that estimating model parameters from reactance measures avoids problems imposed by series resistance effects, since these measures are not influenced by series resistance (see Materials and Methods).

Figure 8 shows the average input capacitance obtained, using $\mathrm{AC}$ analysis, from the same cells as in Figure 6, as a function of holding potential, before and after gadolinium treatment (symbols correspond to those in Fig. 6). A significant nonlinear capacitance is present at potentials near the normal resting potential in vivo, $-70 \mathrm{mV}$. As was evident in the time domain analysis (Fig. 6B), AC measures indicate that treatment with gadolinium ions reduces the magnitude of the voltage-dependent capacitance and does not merely shift its voltage dependence. Supporting cells (Deiters and I Iensen) demonstrate no or very little nonlinear capacitance when analyzed in the frequency domain (Fig. 8, open diamonds). OHC peak nonlinear capacitance occurs at potentials that are shifted about $17 \mathrm{mV}$ in the hyperpolarizing direction compared to step analyses. Since holding potentials were different for the $\mathrm{AC}$ and time domain analyses, it is conceivable that initial conditions may be responsible for the shift. Such effects have been found for $\mathrm{Na}$
Figure 9. Demonstration of absence of gating charge immobilization or mechanical response decay. $A$, An $\mathrm{OHC}$ was held at $-80 \mathrm{mV}$, and gating currents were obtained with the $\pm P$ method for a range of voltage step durations. Traces are overlaid, and the occurrence of equivalent off-charge movement at differing pulse widths indicates absence of charge immobilization in this time frame. Charge immobilization would have been indicated by a decreasing offcharge movement as a function of increasing pulse duration. $B, \mathrm{An} \mathrm{OHC}$ was stepped to $+40 \mathrm{mV}$ from a holding potential of $-80 \mathrm{mV}$ for about $20 \mathrm{msec}$, and the mechanical response was measured with the differential photodiode technique. Downward deflection is contraction. Note absence of decay in the mechanical response during depolarization.
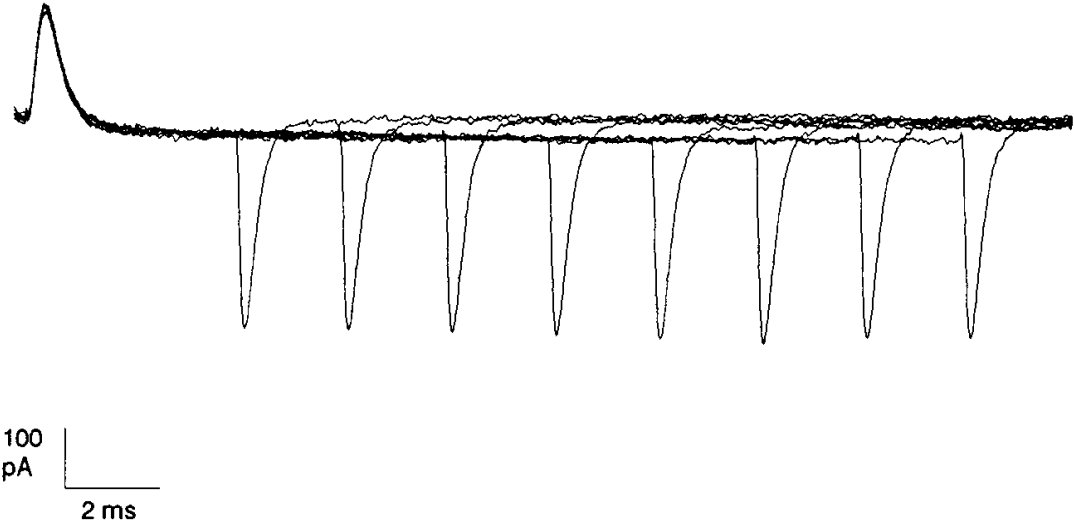

B

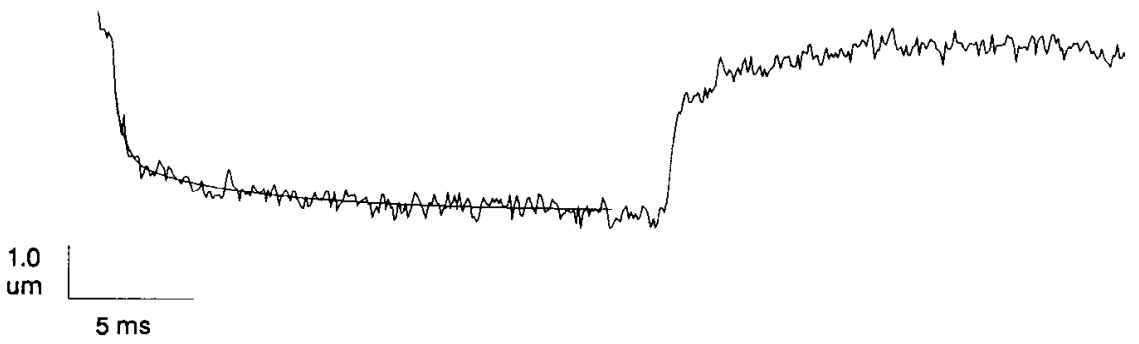



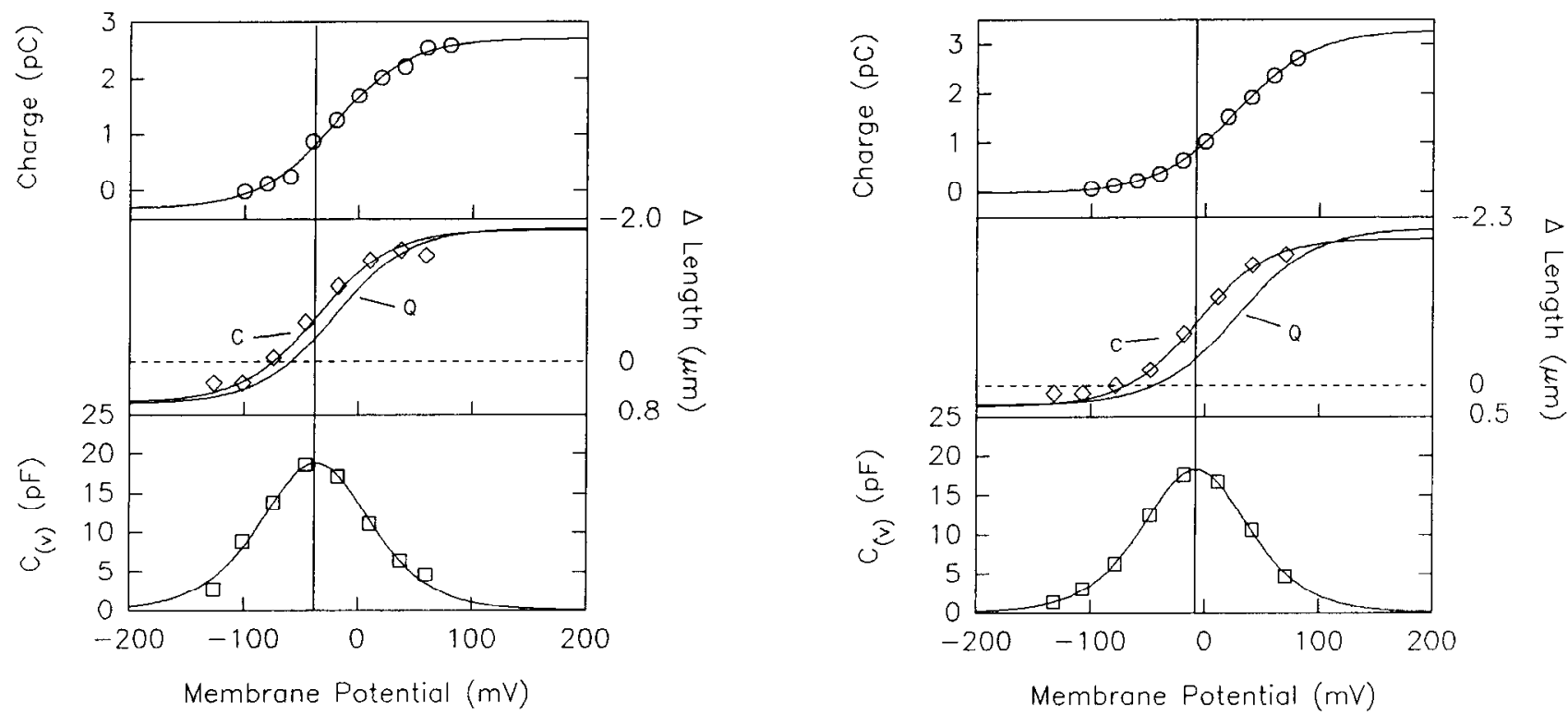

Figure 10. Comparison of AC-determined capacitance (open squares), step-determined charge movement (open circles), and mechanical response (open diamonds) for two OHCs demonstrating differing $V_{h}$. Comparison indicates that voltage dependence of mechanical response more closely corresponds to voltage dependence of capacitance derived from AC analysis ( $V_{h}$ of AC measures indicated by vertical lines through plots) than to voltage dependence derived from step analysis. OHC mechanical responses were measured off the video monitor with the differential optoresistor. $A$, Parameters determined from charge movement measures (open circles): $V_{h},-21 \mathrm{mV} ; z, 0.78$. Parameters determined from AC capacitance measures (open squares): $V_{h},-37 \mathrm{mV} ; z, 0.79$. Mechanical response (open diamonds) is plotted along with scaled Boltzmann functions using $V_{h}$ and $z$ values obtained from charge data $(Q)$ or capacitance data $(C)$. Note the closer correspondence of the mechanical data points with the function obtained from the capacitance fit $(C)$. No direct cell perfusion. $\mathrm{CsCl}$ electrode, no EGTA. Bath perfusion contained $20 \mathrm{~mm}$ TEA, $20 \mathrm{~mm} \mathrm{CsCl}, 2$ $\mathrm{mM} \mathrm{CoCl}$, and no added $\mathrm{Ca}^{2+} . B$, Parameters determined from charge movement measures (open circles): $V_{h}, 26.7 \mathrm{mV} ; z, 0.75$. Parameters determined from AC capacitance measures (open squares): $V_{h},-8 \mathrm{mV} ; z, 0.82$. Mechanical response (open diamonds) is plotted along with scaled Boltzmann functions using $V_{h}$ and $z$ values obtained from charge data $(Q)$ or capacitance data $(C)$. Note the closer correspondence of the mechanical data points with the function obtained from the capacitance fit $(C)$. Cell individually perfused with $20 \mathrm{~mm} \mathrm{TEA}_{2} 20 \mathrm{~mm} \mathrm{CsCl}, 2 \mathrm{~mm} C \mathrm{CoCl}$, and no added $\mathrm{Ca}^{2+}$ medium from one barrel of a double-barreled pipette whose other barrel contained an additional $1 \mathrm{~mm}^{\mathrm{GdCl}}{ }_{3}$. Bath perfusion as above. $\mathrm{CsCl}$ electrode, no EGTA.

channel nonlinear charge movement (Bezanilla et al., 1982b; Fernández et al., 1982). In that case, charge immobilization ${ }^{s}$ as well as long-term inactivation may contribute to apparent voltage shifts. However, in the OHC charge immobilization is absent, since off-gating charge magnitude is not time dependent (Fig. $9 A$ ). In addition, unlike Na currents, OHC mechanical responses demonstrate no decay during prolonged depolarizations (Fig. 9B, see Fig. 11).

The differing voltage dependencies of $\mathrm{OHC}$ nonlinear capacitance obtained with the two measurement techniques used here may be due to problems that are associated with the step analysis technique (see Discussion). It is suggested that the AC analysis result more accurately reflects the voltage dependency of nonlinear capacitance. It is of interest, therefore, to make comparisons between the voltage dependence of $\mathrm{OHC}$ motility and the voltage dependence of nonlinear capacitance obtained by $\mathrm{AC}$ or step analysis. Figure 10 demonstrates for two $\mathrm{OHCs}$ that the voltage dependence of $\mathrm{OHC}$ motility corresponds more closely to the voltage dependence of nonlinear capacitance obtained by

\footnotetext{
${ }^{5}$ Charge immobilization refers to magnitude inequalities of on- and off-gating charge generated by a voltage step. These measures are thought to reflect processes involved in fast inactivation and long-term depolarization-induced slow inactivation of $\mathrm{Na}$ currents. That is, there is a decrease in off-gating charge relative to on charge that is time dependent; the time course is correlated with the time course of Na current inactivation (for review, see Hille, 1984).
}

the $\mathrm{AC}$ method, rather than that obtained by step analysis. This result may be due to an inaccurate estimate of the voltage dependency of $\mathrm{OHC}$ nonlinear capacitance by step analysis.

It is conceivable that voltage-induced length changes may cause deformation of the $\mathrm{OHC}$ membrane (stretching and contracting), leading to changes in the specific membrane capacitance. Therefore, it is necessary to determine the possible contribution of such a phenomenon to the measured nonlinear capacitance. This issue was directly evaluated by taking advantage of the observations of Brownell et al. $(1989 \mathrm{a}, \mathrm{b})$ that cell turgor governs the robustness of electrically induced $\mathrm{OHC}$ motility. That is, experiments were performed to determine whether gating currents are abolished when $\mathrm{OHC}$ longitudinal motility is inhibited due to loss of cell turgor. Utilizing fairly large-tipped patch pipettes $(\sim 2 \mu \mathrm{m})$, it is possible to induce reversible cytosolic volume changes rapidly by applying slight suction or pressure to the pipette. Such was the case for the ccll depicted in Figure 11. Length changes induced by depolarizing the cell from -80 to $+40 \mathrm{mV}$ were absent when the cell's cytosol was removed. Immediately upon refilling the cell, the length changes were robust. The effect can be reversibly repeated as long as the whole-cell configuration is maintained. Gating currents (Fig. $11 E$ ) were not blocked by the cytosolic volume reduction. These results indicate that nonlinear capacitance is not a function of membrane deformations induced by longitudinal length changes. 
A

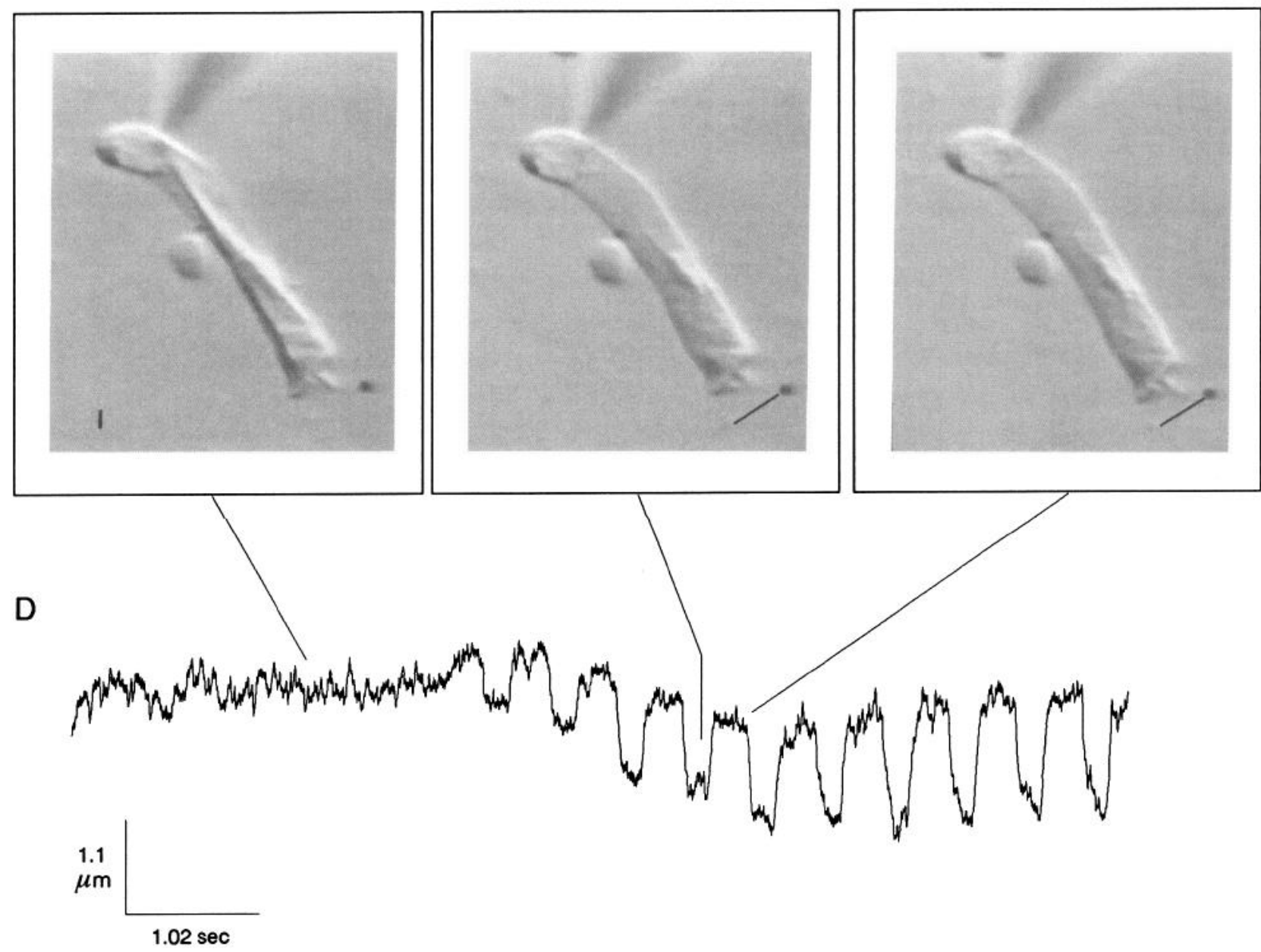

E

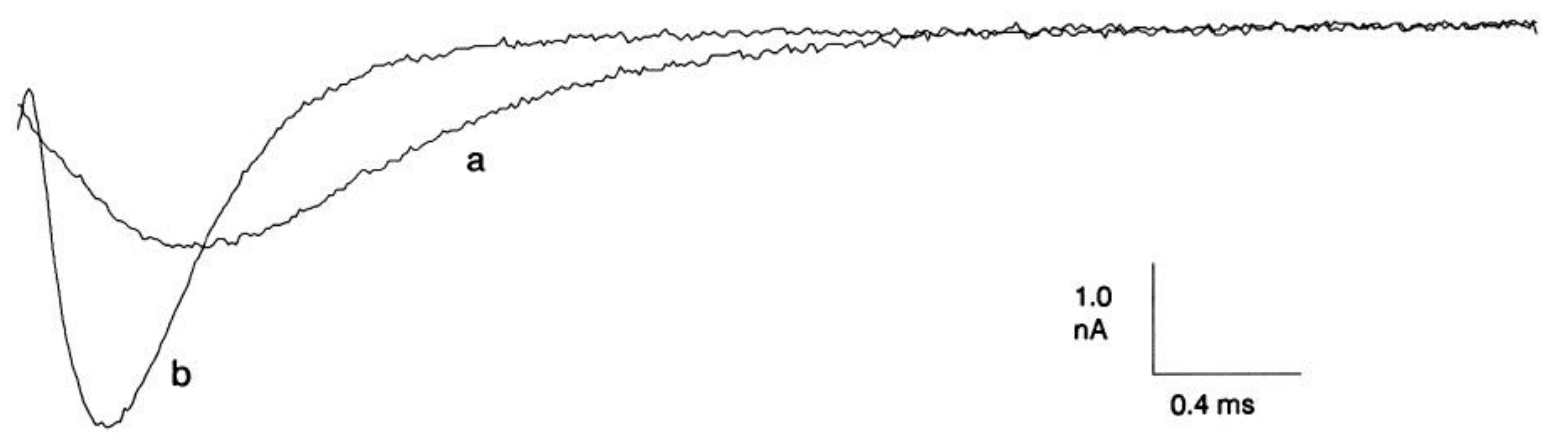

Figure 11. Effect of cytosolic volume alterations on voltage-induced OHC movements: video prints of an OHC that was induced to collapse by gentle suction on the patch electrode located at the nuclear pole of the cell $(A)$ and after restoring normal cell volume by gentle pressure into the pipette ( $B$, during depolarization of the cell to $40 \mathrm{mV}$; and $C$, at the holding potential of $-80 \mathrm{mV}$ ). Scale bar in $A, 3 \mu \mathrm{m}$. Simultaneously collected trace of cuticular plate movements $(D)$ indicates that movement was abolished during volume reduction but returned immediately upon volume replacement. Downward deflections indicate contraction. Traces in $E$ were obtained from a different cell and depict off-gate currents obtained with the $\mathrm{P} /-4$ technique at a step potential of $+80 \mathrm{mV}$ from a holding potential of $-120 \mathrm{mV}$ (nominal). Trace $a$ was collected when the cell was flattened due to loss of turgor, and trace $b$ was obtained immediately after reinflating the cell. Integration indicates that the nonlinear charge movements were roughly equivalent, differing by about $10 \%$, with the deflated condition being larger. This difference may be due to the change in the series resistance before $(11.4 \mathrm{M} \Omega)$ and after $(6.4 \mathrm{M} \Omega)$ reinflation. Series resistance consistently decreases when cells are reinflated by applying pressure to the patch electrode, and this is reflected in the redistribution of charge in time (difference between trace time constants) for conditions $a$ and $b$. 
Under the deflated conditions, slight dimpling of the OHC's lateral membrane coincident with voltage steps was noted. Gadolinium ions can reduce or abolish this voltage-dependent dimpling.

\section{Discussion}

\section{Nonlinear capacitance of the $\mathrm{OHC}$ membrane}

$\mathrm{AC}$ and step analyses presented here demonstrate that $\mathrm{OHC}$ membranes possess a capacitance that is voltage dependent. Previous measures of OHC membrane capacitance (Santos-Sacchi, 1988, 1989c) demonstrated that these cells possess input capacitance values, at holding potentials near in vivo levels, exceeding the typical $1 \mu \mathrm{F} / \mathrm{cm}^{2}$ found in biological membranes. In that study, input capacitance of OHCs from the apical turns of the cochlea averaged near $38 \mathrm{pF}$ (at a holding potential of $-70 \mathrm{mV}$ ), with a specific capacitance of about $1.2 \mu \mathrm{F} / \mathrm{cm}^{2}$. Clearly, the present findings indicate that such large values were due to the significant nonlinear capacitance present at typical in vivo potentials. Ashmore (1987) had also measured OHC membrane capacitance from cells dissociated from the apical turns, reporting an average value of $27 \mathrm{pF}$, which corresponded to estimates based upon a specific capacity of $1 \mu \mathrm{F} / \mathrm{cm}^{2}$. This is surprising since measures were made at holding potentials where the nonlinear capacitance should have been substantial. Subsequently, Ashmore $(1989,1990)$ demonstrated the existence of nonlinear charge movement in OHCs and estimated maximum charge movements of $350 \mathrm{fC}$ for OHCs from the lowfrequency region of the cochlea; it was stated that $5 \%$ of the cell's capacitance is membrane potential sensitive. In the present study, average maximum nonlinear charge transfer was shown to be about $2 \mathrm{pC}$, and step or $\mathrm{AC}$ analysis provided roughly equivalent estimates of peak nonlinear capacitance of about 17 $\mathrm{pF}$; that is, about $40 \%$ of the cell's maximum capacitance is membrane potential sensitive. It is not clear why such large differences exist between the present results and those of Ashmore $(1989,1990)$, although the $\pm P$ technique was exclusively used in that study.

The magnitude of nonlinear capacitance relative to membrane potential follows a bell-shaped function, whereby it increases upon depolarization from highly negative membrane potentials, reaches a maximum, and then declines upon further depolarization. However, the step and $\mathrm{AC}$ analyses utilized in this study give differing voltage dependencies, with the $\mathrm{AC}$ voltage technique indicating a peak capacitance at about $-40 \mathrm{mV}$ and the step technique indicating a peak at about $-23 \mathrm{mV}$. Bezanilla et al. (1982b) have demonstrated that the voltage dependence of nonlinear charge movement duc to $\mathrm{Na}$ channel gating is dependent upon holding potential, that is, the initial conditions prior to charge movement measurement. This dependence is thought to be related to processes underlying the inactivation of sodium currents. Although the holding potentials were different for the two measuring techniques used in this study, it is unlikely that a voltage shift due to initial conditions as occurs for the Na channel is responsible for the present results. That is, it was shown that charge immobilization is absent in the $\mathrm{OHC}$, at least during the time window reported here. Correspondingly, the $\mathrm{OHC}$ mechanical response does not inactivate, even for durations up to $500 \mathrm{msec}$ (Fig. 11). Furthermore, prolonged depolarization (up to $2 \mathrm{~min}$ at $0 \mathrm{mV}$, followed by return to $-80 \mathrm{mV}$ ) also has no apparent effect on gating currents or mechanical responses. Still, initial condition effects should be evaluated more systematically.
There are several problems with the step analysis technique that are not encountered with the AC technique. First, because of series resistance, a true voltage step is not delivered to the cell because of the large capacitive currents generated, and consequently the voltage applied across the cell membrane is significantly less depolarized during step depolarizations than is commanded, even at steady state. In addition, due to the voltage-dependent capacitance, the clamp time constant, and consequently the time course of membrane potential change, will vary at different levels of step depolarizations, as it depends upon cell capacitance and series resistance. Nevertheless, the total charge movement should be independent of the time it takes to reach steady state, and correcting voltages for series resistance effects using steady state, non-leak-subtracted current levels should prove sufficient. Unfortunately, the on-line subtraction protocol to extract nonlinear charge movement $(\mathrm{P} /-4)$ is based on the assumption that series resistance effects are absent. That is, the protocol simply measures linear charge movement at a selected potential and scales that charge movement prior to subtraction based on nominal voltages, without taking into account nonlinear leakage current, which can often be a confounding factor in time domain analysis (Fernández et al., 1982). Thus, scaling inaccuracies may arise and may depend upon the value of the series resistance. Furthermore, in the present experiments the subtraction potential $(-120 \mathrm{mV})$ used for removal of linear charge displacement still falls within the region where some nonlinear charge contributes, as is evident in the AC data. Thus, subtraction values include linear as well as nonlinear components, and this may further contribute to an apparent voltage shift between step and $\mathrm{AC}$ data. Other problems associated with comparisons between time and frequency domain measures of nonlinear capacitance have been discussed by Fernández et al. (1982). While holding the $\mathrm{OHC}$ at very hyperpolarized subtraction levels would permit a more accurate step analysis, such potentials are difficult to use because the cellelectrode setup becomes unstable. Despite these problems and the differing voltage dependencies ${ }^{6}$ derived from the $\mathrm{AC}$ and step techniques, both methods indicate similar estimates of peak nonlinear capacitance in the $\mathrm{OHC}$.

Measures of the gating currents associated with ionic channel activation have been useful in estimating the number of channels within a membrane (see Hille, 1984). Estimates are achieved by comparing the voltage-dependent characteristics of charge movement to those characteristics of the processes that are controlled by such charge movements (e.g., ion conductance). For example, Nonner et al. (1975) determined that two particles with an effective charge of $-1.65 e^{-}$move within the membrane to activate the sodium channel in frog node of Ranvier. This was determined by computing the ratio of effective valence $(z)$ of the sodium conductance-voltage $\left(g_{\mathrm{Na}}-V\right)$ function to that of the $Q-V$ function associated with channel activation. Since total nonlinear charge was $17,200 e \cdot / \mu \mathrm{m}^{2}$ in their preparation, the number of channels was estimated to be $5212 / \mu \mathrm{m}^{2}$ [i.e., $17,200 /$ $(2 \times 1.65)]$. In a similar manner, the number of voltage sensors within the $\mathrm{OHC}$ membrane can be estimated. The average total nonlinear charge $\left(Q_{\max }\right)$ of about $2 \mathrm{pC}$ per OHC observed in the

\footnotetext{
${ }^{6}$ It should be reemphasized that voltage-dependent processes are susceptible to the ionic makeup (charge screening ability) of the medium that bathes the plasmalemma. Thus, the in vitro voltage dependence of nonlinear capacitance and motility shown here may not reflect in vivo conditions.
} 
present study translates to about $3850 \mathrm{e} / \mu \mathrm{m}^{2}$. Assuming that this charge movement is associated with the motility of the cell, the similarity of the valences of $\mathrm{OHC}$ length changes and charge movement indicates the existence of a single voltage-sensing particle with an absolute charge magnitude close to $1 e^{-}$. Thus, the number of voltage-sensing particles within the $\mathrm{OHC}$ membrane approaches $4000 / \mu \mathrm{m}^{2}$. These particles presumably represent the voltage sensors of independent, membrane-bound motor elements. In fact, Dallos et al. (1991) have elegantly shown that, indeed, OHC motility is driven by independent motor elements distributed in the basolateral region of the cell. They extend from nuclear to cuticular regions, that is, roughly paralleling the extent of the subsurface cisternae. Interestingly, the number of motor elements inferred from charge movement data reported here is of the same order of magnitude as the number of tightly packed $10 \mathrm{~nm}$ intramembranous particles recently observed by Kalinec et al. (1991). These investigators have speculated that the intramembranous particles represent the $\mathrm{OHC}$ motor units.

Initial observations that $\mathrm{OHC}$ motility and gating currents were blocked by gadolinium ions (Santos-Sacchi, 1989a) raised the possibility that voltage-dependent stretch-activated channels may underlie the observed gating and mechanical events through some sort of reverse process, since it had been shown that gadolinium is a potent blocker of stretch-activated channels (Yang and Sachs, 1989). In fact, voltage-dependent stretch-activated channels have been found in the lateral membrane of the OHC (Ding et al., 1989, 1991), but the channel number is probably too low to account for the observed charge displacement.

Interestingly, Ashmore (1987) ruled out any interaction between plasma membrane and the extensive intracellular subsurface cisternal membrane system of the OHC because his calculations indicated that $\mathrm{OHC}$ capacitance can be accounted for by linear dielectric plasmalemmal properties. Since it is now clear that $\mathrm{OHC}$ capacitance is not simply due to linear membrane properties, possible voltage-dependent electrical interactions between these two membranous systems should be considered. However, similar considerations concerning a possible voltage-dependent recruitment of a hypothetically unavailable portion of transverse tubular membrane capacitance in striated muscle have proved untenable (Chandler et al., 1976). Indeed, there is rather good evidence now that the bulk of nonlinear charge displacement in striated muscle is afforded by dihydropyridine-sensitive calcium channels (Adams et al., 1990). It may be that most of the nonlinear charge movement in $\mathrm{OHCs}$ is associated with intramembranous voltage sensors responsible for OHC motility, but certainly the issue of a subsurface cisternal contribution is not yet resolved. However, it is unlikely that the nonlinear capacitance is a function of membrane deformations caused by length changes since charge movement is still measured during loss of cell turgor, which abolishes longitudinal movement. Also, changes in membrane dielectric properties due to electrostriction can be ruled out based on the arguments of Chandler et al. (1976). It should also be pointed out that a possible contribution may come from gating currents associated with ionic channels within the $\mathrm{OHC}$ membrane. Regardless of the underlying mechanisms that contribute to the voltage-dependent capacitance, its existence will alter the $\mathrm{RC}$ time constant of the $\mathrm{OHC}$ in a voltage-dependent manner, thereby dynamically modifying the receptor potential waveform generated in vivo. This leads to the conclusion that sensing of the stimulus for $\mathrm{OHC}$ motility effectively modifies the stimulus for OHC. motility.

\section{Relation between nonlinear capacitance and cell motility}

As discussed above, the voltage dependence of $\mathrm{OHC}$ fast motility suggests the existence of a corresponding gating current. In other systems, correlation between gating current characteristics and the processes they presumably control provides evidence linking the two. In squid axon, for example, treatments that modify gating current characteristics typically are reflected in measures of $\mathrm{Na}$ currents (Bezanilla and Armstrong, 1974; Armstrong, 1981; although see Tanguy and Yeh, 1988). It is shown here that gadolinium ions are capable of simultaneously reducing or abolishing $\mathrm{OHC}$ motility and gating currents (or nonlinear capacitance). This blockade and the reversibility of gadolinium's effects upon washout may indicate that the two phenomena are dependent. Further evidence linking the two includes their similar voltage dependencies and their similar susceptibility to charge screening. Based on these results, a more detailed study of the concentration-dependent effects of gadolinium is warranted and may lead to quantitative estimates of OHC membrane surface charge.

It is interesting to note that the time course of gating current is a function of clamp time constant, indicating that charge movement is redistributed in time depending upon the speed of transmembrane voltage change. The speed limitations imposed by electrode series resistance prevent an accurate measure of the actual gating time constant, which is probably much faster than can be measured. However, the dependence of gating time constant upon clamp time constant can be used to characterize further the relationship between charge movement and OHC motility. Thus, it has been shown that the speed or frequency response of $\mathrm{OHC}$ motility increases in parallel with clamp time constant or correspondingly with gate time constant (SantosSacchi, 1990a).

\section{Cell turgor requirement for fast motility}

Brownell et al. (1989a,b) have demonstrated that prolonged depolarization of the $\mathrm{OHC}$ under voltage clamp or treatments with salicylates causes a decrease in OHC cytoplasmic turgor. The process is slow and reversible (on the order of tens of minutes) and is accompanied by a reduction or abolition of longitudinal OHC motility, which also recovers upon restoration of cell turgor. The results presented here demonstrate directly that the reduction of cytosolic volume is one factor responsible for the reduction in $\mathrm{OHC}$ motility, since holding potential was held constant and no exogenous treatments were involved. This clearly confirms the hypothesis of Brownell and colleagues that cell turgor is directly involved in the robustness of electrically evoked OHC motility. Cell turgor may underlie the translation of voltage-dependent membrane phenomena to longitudinal force generation. Indeed, gating currents remain intact during cell turgor alterations. The observation of depolarization-induced membrane dimpling, which was susceptible to gadolinium treatment, during loss of cell turgor further suggests that the membrane-associated portion of the OHC motility mechanism remained intact and was simply uncoupled from a longitudinal translation process. It is conceivable that loss of cell volume disrupts elements linking a motility voltage sensor and subsurface structures; however, clearly, such a disruption must be reversible on a time scale of tens of minutes, at least (Brownell et al., 1989a,b). The study of the intricate subplas- 
malemmal cytoskeleton and cisterns of the $\mathrm{OHC}$ may provide clues needed to understand the translational process (Bannister et al., 1988; Slepecky, 1989; Evans, 1990; Holley and Ashmore, 1990; Dieler et al., 1991).

For some time, anecdotal observations of isolated $\mathrm{OHCs}$ have led to the idea that the intracellular pressure of the $\mathrm{OHC}$ is greater than extracellular pressure. For example, OHCs often burst when impaled with microelectrodes, cjccting cytoplasm and intracellular organelles (Brownell, 1983). Kaufman and Brownell (1991) have recently provided indirect evidence confirming this notion. Considering the dependence of longitudinal motility upon cell turgor, it is now clear that estimates of the magnitude of $\mathrm{OHC}$ motility may require reinspection. That is, measures of the voltage versus length function of OHCs have been made with the use of the whole-cell voltage-clamp configuration, where inherently the cells' internal turgor pressure is compromised by establishing contiguity between cell and pipette interiors (Ashmore, 1987; Santos-Sacchi and Dilger, 1988; Santos-Sacchi, 1989c). For example, Santos-Sacchi (1989c) estimated that near the normal in vivo resting potential, $-70 \mathrm{mV}$, the response of the $\mathrm{OHC}$ is about $2 \mathrm{~nm} / \mathrm{mV}$; at that holding potential the cells reside near the hyperpolarizing saturation area of the response function. Based on these observations and on evidence indicating the voltage dependence of $\mathrm{OHC}$ motility (Santos-Sacchi and Dilger, 1988), a calculated disparity of 21 $\mathrm{dB}$ exists between threshold hasilar membrane motion and $\mathrm{OHC}$ motion at high frequencies (see Santos-Sacchi, 1989c). Obviously, this leads to difficulties in assigning the role of "cochlear amplifier" solely to OHCs. It is now clear that these measures of OHC movement may be underestimates, though certainly not approaching an order of magnitude. Nevertheless, nonintracellular techniques, such as that used by Evans et al. (1989), may provide more accurate estimates of movement magnitude since cell turgor is not directly compromised. Still, these techniques pose other problems; notably, membrane potential must be estimated and cannot be directly measured or controlled with the precision of the whole-cell voltage-clamp technique.

The evidence linking basilar membrane mechanics to $\mathrm{OHC}$ function is growing (Ruggero and Rich, 1991). Currently, the most likely candidate responsible for this interaction is the motility of the $\mathrm{OHC}$, which has recently been shown to have a much wider frequency response than previously thought, the 3 $\mathrm{dB}$ break frequency of which approaches $1 \mathrm{kHz}$ (Santos-Sacchi, 1990a). Although many basic properties of the OHC and its motility have been detailed, the molecular basis of this motility remains to be determined and no doubt promises to be a novel cellular adaptation designed to meet the mammals' high frequency communicative requirements.

Note added in proof. Ashmore presented data on the nonlinear capacitance of OHCs in the published proceedings of the Taniguchi International Symposium on Visual Science [Neurosci Res, Suppl 12 (1990) S39-S50], which indicate larger values of nonlinear capacitance than his other reports. Experimental methods were not detailed, but estimates of capacitance were obtained at different holding potentials by integration of the charging transient prcsumably induced by a small voltage step. His data appear to be in general agreement with the capacitance data reported here.

\section{References}

Adams BA, Tanabe T, Mikami A, Numa S, Beam KG (1990) Intramembrane charge movement restored in dysgenic skeletal muscle by injection of dihydropyridine receptor cDNAs. Nature 346:569-572. Armstrong CM (1981) Sodium channels and gating currents. Physiol Rev 61:644-683.

Armstrong CM, Bezanilla F (1973) Currents related to movement of the gating particles of the sodium channels. Nature 242:459-461.

Ashmore JF (1987) A fast motile response in guinea-pig outer hair cells: the cellular basis of the cochlear amplifier. J Physiol (Lond) 388 : 323-347.

Ashmore JF (1989) Transducer motor coupling in cochlear outer hair cells. In: Mechanics of hearing (Kemp D, Wilson JP, eds), pp 107113. New York: Plenum.

Ashmore JF (1990) Mechanoreception. In: Sensory transduction (Borsellino A, Cervetto L, Torre V, eds), pp 25-50. New York: Plenum.

Bannister LH, Dodson HC, Astbury AF, Douek EE (1988) The cortical lattice: a highly ordered system of subsurface filaments in guinea pig cochlear outer hair cells. Prog Brain Res 74:213-219.

Bezanilla F, Armstrong CM (1974) Gating currents of the sodium channel: three ways to block them. Scicnce 183:753-754.

Bezanilla F, Armstrong CM (1977) Inactivation of the sodium channel. I. Sodium current experiments. J Gen Physiol 70:549-566.

Bezanilla F, White MM, Taylor RE (1982a) Gating currents associated with potassium channel activation. Nature 296:657-659.

Bezanilla F, Taylor RE, Fernández JM (1982b) Distribution and kinetics of membrane dielectric polarization. I. Long-term inactivation of gating currents. J Gen Physiol 79:21-40.

Brown MC, Nuttall AL (1984) Efferent control of cochlear inner hair cell responses in the guinea-pig. J Physiol (Lond) 354:625-646.

Brownell WE (1983) Observations on a motile response in isolated outer hair cells. In: Mechanisms of hearing (Webster WR, Aitken LM, eds), pp 5-10. Clayton, Australia: Monash UP.

Brownell WE, Bader CR, Bertrand D, de Ribaupierre Y (1985) Evoked mechanical responses of isolated cochlear outcr hair cells. Scicnce 227:194-196.

Brownell WE, Imredy JB, Shehata W (1989a) Stimulated volume changes in mammalian outer hair cells. Proc Annu Int Cong IEEEEng Med Biol Soc 11:1344-1345.

Brownell WE, Shehata W, Imredy JB (1989b) Slow electrically and chemically evoked volume changes in guinea pig outer hair cells. In: Biomechanics of active movement and deformation of cells (Akas $\mathrm{N}$, ed). pp 493-498. New York: Springer.

Chandler WK, Rakowski RF, Schneider MF (1976) A non-linear voltage dependent charge movement in frog skeletal muscle. J Physiol (Lond) 254:245-283.

Dallos P, Harris D (1978) Properties of auditory nerve responses in absence of outer hair cells. J Neurophysiol 41:365-383.

Dallos P, Santos-Sacchi J, Flock $\AA$ (1982) Intracellular recordings from outer hair cells. Science 218:582-584.

Dallos P, Evans BN, Hallworth R (1991) On the nature of the motor element in cochlear outer hair cells. Nature 350:155-157.

Dieler R, Shehata-Dieler WE, Brownell WE (1991) Concomitant salicylate-induced alterations of outer hair cell subsurface cisternae and electromotility. J Neurocytol, in press.

Ding JP, Salvi RJ, Sachs F (1989) Stretch activated ion channels in outer hair cells from the guinea pig cochlea. Paper presented at the midwinter meeting of the Association for Research in Otolaryngology, St. Petersburg, FL, February.

Ding JP, Salvi RJ, Sachs F (1991) Stretch-activated ion channels in guinea pig outer hair cells. Hear Res, in press.

Evans B, Dallos P, Hallworth R (1989) Asymmetries in motile responses of outer hair cells in simulated in vivo conditions. In: Mechanics of hearing (Kemp D, Wilson JP, eds), pp 205-206. New York: Plenum.

Evans BN (1990) Fatal contractions: ultrastructural and electromechanical changes in outer hair cells following transmembranous electrical stimulation. Hear Res 45:265-282.

Evans MG, Fuchs PA (1987) Tetrodotoxin-sensitive, voltage-dependent sodium currents in hair cells from the alligator cochlea. Biophys J 52:649-652.

Fernández JM, Bezanilla F, Taylor RE (1982) Distribution and kinetics of membrane dielectric polarization. II. Frequency domain studies of gating currents. J Gen Physiol 79:41-67.

Fishman HM, Moore LE, Poussart D (1977) Asymmetry currents and admittance in squid axons. Biophys $J$ 19:177-183.

Harrison RV, Evans EF (1979) Cochlear fiber responses in guinea pigs with well defined cochlear lesions. Scand Audiol Suppl 9:83-92. 
Hille B (1984) Ionic channels of excitable membranes. Sunderland, MA: Sinauer.

Hodgkin AL, Huxley AF (1952) A quantitative description of membrane current and its application to conduction and excitation in nerve. J Physiol (Lond) 117:500-544.

Holley MC, Ashmore JF (1988) On the mechanism of a high frequency force generator in outer hair cells isolated from the guinea pig cochlea. Proc R Soc Lond [Biol] 232:413-429.

Holley MC, Ashmore JF (1990) Spectrin, actin and the structure of the cortical lattice in mammalian cochlear outer hair cells. J Cell Sci 96:283-291.

Hubbard AE, Mountain DC (1983) Alternating current delivered into the scala media alters sound pressure at the eardrum. Science 222: $510-512$.

Iurato S, Franke K, Luciano L, Wermbter G, Pannese E, Reale E (1976) Intercellular junctions in the organ of Corti as revealed by freeze fracturing. Acta Otolaryngol (Stockh) 82:57-69.

Iwasa KH, Kachar B (1989) Fast in vitro movement of outer hair cells in an external electric field: effect of digitonin, a membrane permeabilizing agent. Hear Res 40:247-254.

Kachar B, Brownell WE, Altschuler R, Fex J (1986) Electrokinetic shape changes of cochlear outer hair cells. Nature 322:365-368.

Kalinec F, Iwasa K, Lim DJ, Kachar B (1991) Dynamic and structural characterization of a voltage dependent motor in the lateral wall of outer hair cells. Paper presented at the midwinter meeting of the Association for Research in Otolaryngology, St. Petershurg, FL, February.

Katz B, Miledi R (1967) A study of synaptic transmission in the absence of nerve impulses. J Physiol (Lond) 192:407-436.

Kaufman G, Brownell WE (1991) Determination of the cytoplasmic pressure of the cochlear outer hair cell. Paper presented at the midwinter meeting of the Association for Research in Otolaryngology, St. Petersburg, FL, February.

Kemp DT (1978) Stimulated acoustic emissions from within the human auditory system. J Acoust Soc Am 64:1386-1391.

Lin X, Hume RL, Nuttall AL (1990) Voltage-gated $\mathrm{Ca}^{2+}$ currents recorded in vitro from outer hair cells of the guinea pig. Paper presented at the 20th annual meeting of the Society for Neuroscience, St. Louis, MO, October.

Marty A, Neher E (1983) Tight-seal whole-cell recording. In: Singlechannel recording (Sakmann B, Neher E, eds), pp 107-122. New York: Plenum.

Mountain DC, Hubbard AE, McMullen TA (1983) Electromechanical processes in the cochlea. In: Mechanics of hearing (de Boer E, Viergever MA, eds), pp 119-126. Delft, The Netherlands: Delft UP.

Nonner W, Rojas E, Stampfli R (1975) Displacement currents in the node of Ranvier: voltage and time dependence. Pflugers Arch 354:118.

Oesterle E, Dallos P (1988) Indirect evidence for the absence of electrotonic coupling between hair and support cells in the mammalian cochlea. J Acoust Soc Am [Suppl 1] 83:S97.
Ogden DC, Stanfield PR (1987) Introduction to single channel recording. In: Microelectrode techniques (Standen NB, Gray PTA, Whitaker MJ, eds), pp 63-81. Cambridge: Company of Biologists.

Patuzzi RB, Yates GK, Johnstone BM (1989) Outer hair cell receptor currents and sensorineural hearing loss. Hear Res 42:47-72.

Ruggero MA, Rich NC (1991) Furosemide alters organ of Corti mechanics: evidence for feedback of outer hair cells upon the basilar membrane. J Neurosci 11:1057-1067.

Salzberg BM, Bezanilla F (1983) An optical determination of the series resistance in Logigo. J Gen Physiol 82:807-817.

Santos-Sacchi J (1988) Whole cell voltage clamp studies on isolated outer hair cells. Paper presented at symposium, Current concepts of hair cell function: a consensus meeting. Kresge Hearing Research Institute, University of Michigan, Ann Arbor, MI, June.

Santos-Sacchi J (1989a) Gadolinium ions reversibly block voltage dependent movements of isolated outer hair cells. Paper presented at the 19th annual meeting of the Society for Neuroscience, Phoenix, AZ, October.

Santos-Sacchi J (1989b) Calcium currents, potassium currents and the resting potential in isolated outer hair cells. Paper presented at the midwinter meeting of the Association for Research in Otolaryngology, St. Petersburg, FL, February.

Santos-Sacchi J (1989c) Asymmetry in voltage dependent movements of isolated outer hair cells from the organ of Corti. J Neurosci 9:29542962.

Santos-Sacchi J (1990a) Fast outer hair cell motility: how fast is fast? In: The mechanics and biophysics of hearing (Dallos P, Geisler CD, Matthews JW, Ruggero MA, Steele CR, eds). Berlin: Springer.

Santos-Sacchi J (1990b) Nonlinear voltage dependent capacitance of the outer hair cell $(\mathrm{OHC})$ membrane. Paper presented at the 120 th meeting of the Acoustical Society of America, San Diego, CA, November.

Santos-Sacchi J (1991) Isolated supporting cells from the organ of Corti: some whole cell electrical characteristics and estimates of gap junctional conductance. Hear Res 52:89-98.

Santos-Sacchi J, Dilger JP (1988) Whole cell currents and mechanical responses of isolated outer hair cells. Hear Res 35:143-150.

Schanne OF, Ruiz P.-Ceretti E (1978) Impedance measures in biological cells. New York: Wiley.

Slepecky N (1989) Cytoplasmic actin and cochlear outer hair motility. Cell Tissue Res 257:69-75.

Takashima S (1978) Frequency domain analysis of asymmetry current in squid axon membrane. Biophys J 22:115-119.

Tanguy J, Yeh JZ (1988) Batrachotoxin uncouples gating charge immobilization from fast $\mathrm{Na}$ inactivation in squid giant axons. Biophys J 54:719-730.

Yang XC, Sachs F (1989) Block of stretch-activated ion channels in Xenopus oocytes by gadolinium and calcium ions. Science 243:10681070. 